Adv. Mater. 2017, DOI: 10.1002/adma.201702838

DOI: 10.1002/adma.((please add manuscript number))

Article type: Research News

\title{
Metal-Halide Perovskite Transistors for Printed Electronics: Challenges and Opportunities
}

Yen-Hung Lin*, Pichaya Pattanasattayavong*, and Thomas Anthopoulos*

Dr. Y.-H. Lin

Clarendon Laboratory, Department of Physics, University of Oxford, Parks Road, Oxford

OX1 3PU, United Kingdom

E-mail: yen-hung.lin@physics.ox.ac.uk

Dr. P. Pattanasattayavong

Department of Material Science and Engineering, School of Molecular Science and

Engineering, Vidyasirimedhi Institute of Science and Technology (VISTEC), Rayong 21210,

Thailand

E-mail: pichaya.p@vistec.ac.th

Prof. T. D. Anthopoulos

Division of Physical Sciences and Engineering, King Abdullah University of Science and

Technology, Thuwal 23955-6900, Saudi Arabia

E-mail: thomas.anthopoulos@kaust.edu.sa

Keywords: perovskites; thin-film transistors; charge transport; photo-transistors; lightemitting transistors

\section{Abstract}

Following the unprecedented rise in photovoltaic power conversion efficiencies during the past five years, metal-halide perovskites (MHPs) have emerged as a new and highly promising class of solar energy materials. Their extraordinary electrical and optical properties combined with the abundance of the raw materials, the simplicity of synthetic routes and unmatched processing versatility, make MHPs ideal for cost-effective, large-volume manufacturing of a plethora of optoelectronic devices that span far beyond photovoltaics. In this Research News article, we look beyond current applications in the field of energy and optoelectronics to the field of large-area electronics using MHPs as the semiconductor. We first provide an overview of the relevant fundamental material and electronic properties of MHPs from the discussion of crystal structures, electronic states and charge-transport. This is followed by the recent demonstrations of MHP-based transistors including light-sensing and lightemitting transistors. Bringing together the knowledge garnered from theoretical and 
Adv. Mater. 2017, DOI: 10.1002/adma.201702838

experimental work will help the scientific community to expand the application space of MHPs and create new avenues of research.

\section{Introduction}

Driven by the urgent need for climate change mitigation, recent years have witnessed tremendous advances in the field of renewable energy technologies. ${ }^{[1-6]}$ Among the various types of renewable energy sources, harnessing solar irradiation and converting it to useable electrical power using photovoltaic cell has remained a hot area of research primarily due to the abundance of solar energy and the tremendous progress in the science and technology of photovoltaics. ${ }^{[7-10]}$ The key requirements for developing solar panels that are able to produce inexpensive electrical energy include suitable optical absorption with high photon-to-electron conversion efficiency, long operating lifetime, and low cost manufacturing. Metal-halide perovskites (MHPs) represent a novel class of photoactive materials which has demonstrated unmatched potential to address all these requirements. ${ }^{[11-14]}$ Within only a few years since the demonstration of the first perovskite solar cell (PSC), the power conversion efficiency (PCE) has soared from $3.8 \%$ to well above $20 \% .^{[14-16]}$ This is primarily due to the fact that many MHPs combine superior long range crystallinity (even when solution-processed), excellent light absorbing characteristics with superb photon-to-electron conversion efficiency and long-range charge carrier transport. ${ }^{[17]}$ This unique combination of physical properties has allowed the development of high-efficiency PSCs based on simpler and cost-effective, in terms of manufacturing, device architectures such as the planar heterojunction structure. ${ }^{[18-20]}$ These are the primary reasons why MHP materials are now considered to be the most promising photovoltaic technology with an anticipated commercial debut in $2018 .^{[21]}$

Whilst the development of high efficiency PSCs is progressing with unprecedented speed, the research community has also started exploring further opportunities for MHPs in different application sectors. ${ }^{[22-23]}$ For example, the semiconducting properties that many MHPs 
Adv. Mater. 2017, DOI: 10.1002/adma.201702838

offer combined with the large carrier mobility and ambipolar transport character reported ${ }^{[24-28]}$ make them suitable candidates for applications in transistors for large-area electronics. In addition, the complex yet versatile crystalline structures has led to the development of resistive switching memories. ${ }^{[29-30]}$ When compared to other semiconductor technologies, both incumbent and emerging, the family of MHPs offers several advantageous characteristics that are considered necessary for high-volume manufacturing including; unmatched processing versatility, simple and scalable material synthesis and abundance of the raw materials. ${ }^{[31]}$ More importantly, as demonstrated in several reports on large-scale processing techniques for making large-area solar cell modules, ${ }^{[32]}$ the technologies explored and developed for photovoltaic applications could directly be applied to the development of MHP-based transistors for the manufacturing of large-area electronics.

In this Research News article, we aim to summarize the progress achieved to date in the area of MHP transistors with emphasis placed on the challenges faced by the research community and finally provide an outlook on the opportunities offered by this emerging family of electronic materials in the field of large-area optoelectronics. An overview is first provided on the electronic properties of MHPs with particular focus on the charge carrier transport processes. We note that comprehensive reviews of structure and properties of MHPs including optical and optoelectronic properties can be found elsewhere. ${ }^{[31,33-36]}$. The field of MHP-based transistors is then introduced starting with the early demonstration of two-dimensional (2D) MHP devices followed by the recent developments of three-dimensional (3D) MHP transistors and logic circuits. The challenges for developing high performance MHP transistors and circuits are discussed in detail. This is followed by the introduction of two types of bifunctional MHP transistors with combined electro-optical functionality. Finally, the outlook of large-area manufacturing for MHP-based transistors are discussed, and related operational stability and health/environmental impacts are examined. 
Adv. Mater. 2017, DOI: 10.1002/adma.201702838

\section{Crystal Structures, Electronic and Charge Transport Properties of MHPs}

\subsection{Crystal structures}

The general chemical formula of perovskite compounds can be expressed as $\mathrm{ABX}_{3}$, where $\mathrm{A}$ and $\mathrm{B}$ are cations and $\mathrm{X}$ is an anion. In the case of MHPs, the cation $\mathrm{A}$ is a monovalent ion which can be either inorganic $\left(\mathrm{Cs}^{+}\right.$and/or $\left.\mathrm{Rb}^{+}\right)$or organic [e.g., methylammonium (MA) $\mathrm{CH}_{3} \mathrm{NH}_{3}{ }^{+}$, formamidinium (FA) $\mathrm{CH}\left(\mathrm{NH}_{2}\right)_{2}{ }^{+}$, or guanidinium (GA) $\mathrm{C}\left(\mathrm{NH}_{2}\right)_{3}{ }^{+}$] whilst the cation $\mathrm{B}$ is a divalent ion of Group 14 (or traditionally Group IV) such as $\mathrm{Ge}^{2+}, \mathrm{Sn}^{2+}$, or $\mathrm{Pb}^{2+}$. The anion $\mathrm{X}$ in halide-based MHPs is $\mathrm{Cl}^{-}, \mathrm{Br}^{-}$, or $\mathrm{I}^{-}$. In a perovskite structure, the $\mathrm{B}$ and $\mathrm{X}$ ions form octahedra $\mathrm{BX}_{6}$ which arrange three-dimensionally by sharing the octahedral corners (see Figure 1a-c), with the $\mathrm{A}$ ions filling in the interstitial space between the $\mathrm{BX}_{6}$ units. The relative sizes of the ions are found to affect the formability of the perovskite structure. Two structural factors, namely the tolerance factor T.F. and the octahedral factor $O . F$. calculated from the ionic radii $R_{A}, R_{B}$, and $R_{X}$ of $\mathrm{A}, \mathrm{B}$ and $\mathrm{X}$ ions, respectively, have been empirically used to gauge the stability of a perovskite structure. ${ }^{[37]}$ The two parameters are defined as:

$$
T . F .=\frac{R_{A}+R_{X}}{\sqrt{2}\left(R_{B}+R_{X}\right)}
$$

and

$$
\text { O.F. }=\frac{R_{B}}{R_{X}} .
$$

Li et al. ${ }^{[37]}$ found that a stable perovskite structure of halide-based $\mathrm{ABX}_{3}$ compounds can form when $0.81 \leq T . F . \leq 1.1$ and $0.44 \leq O . F . \leq 0.90$. More specifically, when T.F. is close to 1 , the arrangement results in a high-symmetry cubic perovskite structure, as shown in Figure 1a with the $\mathrm{BX}_{6}$ octahedron at the centre of the unit cell and the $\mathrm{X}$ ions occupying the corners. In the case of the archetypal methylammonium lead iodide $\left(\mathrm{MAPbI}_{3}\right)$, the $\alpha$ cubic structure (Figure 1a) is obtained at temperatures above $327 \mathrm{~K}$, below which it transforms into the $\beta$ tetragonal phase (Figure 1b) and then into the $\gamma$ orthorhombic phase (Figure 1c) at $165 \mathrm{~K}^{[38]}$ The 
Adv. Mater. 2017, DOI: 10.1002/adma.201702838

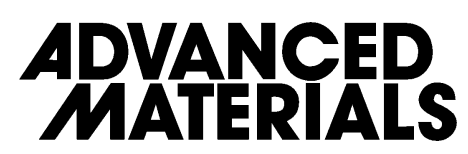

orientation of the organic molecules is random in the $\alpha$ phase, preserving the high symmetry of the cubic phase, and remain disordered in the $\beta$ phase albeit with less freedom. Upon transitioning to the $\gamma$ phase, the orientation of the organic cations then become fixed. ${ }^{[39]}$

\subsection{Electronic properties}

Many computational studies have been dedicated to the investigation of the electronic structure of MHPs with varying degree of complexity and the resulting accuracy (for example, see Ref. ${ }^{[33]}$ and references therein), but in general they yield similar qualitative electronic characteristics. Herein we focus on the widely studied $\mathrm{MAPbI}_{3}$. Starting with its highest-symmetry phase, the $\alpha$ cubic phase, computational results show that the electronic band structure has a direct band gap at the R point or the corner of the Brillouin zone (BZ) [see Figure 1d for an example based on density functional theory with PBE functional (DFT-PBE) calculations] $]^{[40-41]}$ instead of at the center $\Gamma$ point of the BZ as typically observed in conventional semiconductors such as GaAs. Interestingly, the density of states (DOS) shows that the valence band maximum (VBM) is dominated by the I 5 p electrons with some contribution from the $\mathrm{Pb}$ 6s electrons (Figure 1e), ${ }^{[33-}$ ${ }^{34]}$ resulting in the $\sigma$-antibonding $\mathrm{Pb} 6 \mathrm{~s}-\mathrm{I} 5 \mathrm{p}$ orbital (Figure 1f) ${ }^{[42]}$ This reflects the bonding between the electron lone pair in the $\mathrm{Pb} 6 \mathrm{~s}$ orbital and the valence electrons in the I $5 \mathrm{p}$ orbital. The conduction band minimum $(\mathrm{CBM})$ is strongly dominated by the $\mathrm{Pb} 6 \mathrm{p}$ state with slight mixing from the I $5 \mathrm{p}$ state forming the $\pi$-antibonding orbital. ${ }^{[42]}$ The dominance of the anionic I $5 p$ state in the $\mathrm{VB}$ and the cationic $\mathrm{Pb} 6 \mathrm{p}$ state in the $\mathrm{CB}$ reflects the ionic character of $\mathrm{MAPbI}_{3}$ whereas the mixing between $\mathrm{Pb} 6 \mathrm{~s}$ and I 5p near VBM suggests the covalent bonding, representing the mixed ionic-covalent nature of MHPs. ${ }^{[33-34]}$ On the other hand, the electronic signature of the organic cation is found deep in the VB, implying that the organic part only plays a role to stabilize the perovskite structure and to balance the electrostatic charges while having no direct contribution to the electronic properties. ${ }^{[33-34]}$ The charge carrier transport therefore takes place via the three-dimensional scaffold of the $\mathrm{PbI}_{6}$ octahedral. It should be 
Adv. Mater. 2017, DOI: 10.1002/adma.201702838

noted that different computational methods [e.g., different functionals or inclusion of spin-orbit coupling (SOC)] yield similar characteristics, but the differences lie in the size of the band gap and the fine details of the electronic band structure (which may affect further calculations such as charge carrier effective masses). ${ }^{[34]}$ Broadly speaking, for $\alpha-\mathrm{MAPbI}_{3}$ holes will transport via the coupled $\mathrm{Pb} 6 \mathrm{~s}-\mathrm{I} 5 \mathrm{p}$ state whilst electrons will travel mainly through the $\mathrm{Pb} 6 \mathrm{p}$ state. For the $\beta$ tetragonal and $\gamma$ orthorhombic phases of $\mathrm{MAPbI}_{6}$ which exist at lower temperatures, the degree of freedom of the organic cation is limited, resulting in the tilting of $\mathrm{PbI}_{6}$ units and $\mathrm{Pb}$ $\mathrm{I}-\mathrm{Pb}$ bond angle distortions (Figure 1b and 1c); however, their electronic structures do not markedly change, ${ }^{[34,40]}$ which may imply the resilience of the hole and electron transport via the $\mathrm{PbI}_{6}$ units which remain connected in the $\beta$ and $\gamma$ phases.

\subsection{Charge transport}

One of the critical questions raised during the early days of PSCs research was whether the photoexcited species were excitons or free electron-hole pairs $\cdot{ }^{[43]}$ Recent magneto-absorption measurements strongly suggests that MHPs are non-excitonic due to the small binding energy which is found to be $16 \mathrm{meV}$ at low temperatures and estimated to be only a few meV at room temperature. ${ }^{[44]}$ This is also supported by the large dielectric constant (70 or even higher) ${ }^{[45-46]}$ that can effectively screen the electrostatic interaction between electrons and holes. It is noted, however, that the nature of the low-frequency dielectric response is not yet fully understood. ${ }^{[33 \text {, }}$ 47]

Charge carrier transport is typically quantified by the charge carrier mobility $\mu$, which is related to the charge carrier effective mass $m^{*}$ and mean free time between scattering events $\tau$ through: ${ }^{[48]}$

$$
\mu=\frac{q \tau}{m^{*}}
$$


Adv. Mater. 2017, DOI: 10.1002/adma.201702838

where $q$ is the elementary charge. Near the VBM and CBM where hole and electron transport takes place, the effective masses are inversely proportional to the curvature of the approximated parabolic bands. ${ }^{[48]}$ Electronic bands with high curvature are said to be dispersive (the electronic band structure is essentially the $E-k$ dispersion relation), which gives rise to small effective masses and hence high charge carrier mobility.

In the case of $\mathrm{MAPbI}_{3}$, due to the orbital character of $\mathrm{VBM}$ and $\mathrm{CBM}$ coupled with the strong spin-orbit coupling of $\mathrm{Pb}$ which yield highly dispersive electronic bands, the $m^{*}$ of electron and hole are reported to be in the range of $(0.1-0.2) m_{0}$, where $m_{0}$ is the free-electron rest mass, from both theoretical and experimental studies. ${ }^{[3,44,49]}$ The small value of $m^{*}$ leads to the expectation of very high charge carrier mobilities for both electrons and holes in $\mathrm{MAPbI}_{3}$. Ambipolar conductivity is indeed observed, ${ }^{[26,28,50]}$ but the mobility values are more modest and in the range of $1-10 \mathrm{~cm}^{2} \mathrm{~V}^{-1} \mathrm{~s}^{-1}$ for polycrystalline films and only up to $100 \mathrm{~cm}^{2} \mathrm{~V}^{-1} \mathrm{~s}^{-1}$ in single crystals (see Ref. ${ }^{[33]}$ and Ref. ${ }^{[51]}$ and references therein) whereas the carrier mobilities in other inorganic semiconductors are typically higher. For example, PbTe with similar $m^{*}$ values show mobility values of 6,000 and $4,000 \mathrm{~cm}^{2} \mathrm{~V}^{-1} \mathrm{~s}^{-1}$ for electrons and holes, respectively. ${ }^{[48]}$

Based on Eq. (3), this implies either that the charge transport in $\mathrm{MAPbI}_{3}$ is limited by scattering (short scattering time) or that the effective mass is in fact larger. Regarding the former, impurity scattering may be ruled out as MHPs show excellent tolerance to defects (see below), and their large dielectric constant can effectively screen charged impurities. Also, the inverse temperature dependence of mobility $\sim T^{-1.5}$ suggests transport may be limited by acoustic phonon scattering. ${ }^{[52-53]}$ The mechanically soft nature of MHPs ${ }^{[54-55]}$ could be the basis of the strong electron-phonon coupling that makes scattering dominant. On the other hand, the strong coupling could lead to polaronic transport which yields reduced mobility due to larger effective mass. ${ }^{[55]}$ In this regard, small polarons are not likely as the carrier mobility is still relatively high and the transport is not temperature-activated. The more viable picture is the large polaron, especially when taking in account the softness and large dielectric constant of MHPs. ${ }^{[56-57]}$ 
Adv. Mater. 2017, DOI: 10.1002/adma.201702838

Recent studies using the large polaron model give calculated mobility numbers close to the values measured experimentally. ${ }^{[57-58]}$ The discrepant measured small effective mass of $\sim 0.1 m_{0}{ }^{[44]}$ is possibly that of a bare charge carrier before forming a polaron (due to the timescale of the experiment). ${ }^{[56]}$ Nevertheless, further investigation of the polaronic model is still required, for example, to elucidate the temperature dependence and to fully take into account the complex dynamic nature of MHPs.

The dynamic elements in MHP crystal structures are not limited to phonons but further complicated by the extra motion of the organic molecules. ${ }^{[59-60]}$ For $\mathrm{MAPbI}_{3}$ at intermediate and high temperatures ( $\alpha$-cubic and $\beta$-tetragonal phases), the MA cations are constantly moving with vibrational and rotational motions on the time scale of picoseconds. ${ }^{[60]}$ Upon transforming into the $\gamma$-orthorhombic phase, the organic molecules become locked in place, and an abrupt phase transition is observed. ${ }^{[38]}$ The orientation and motion of the organic cations are coupled to the dynamic deformation of the $\mathrm{PbI}_{6}$ units, for example via the steric effects and the hydrogen bonding between $\mathrm{NH}_{3}$ and I. Even though the organic molecules do not contribute directly to the charge carrier transport states near the VBM and CBM of MHPs, their motion is coupled to the $\mathrm{PbI}_{6}$ framework, adding more dynamic components to the electronic band structure and possibly still affecting the charge carrier transport. ${ }^{[61-62]}$ One possible evidence is the sudden increase in the Hall mobility when the cubic phase transforms into the tetragonal phase that may result from the limited degree of freedom of the organic molecules in the latter phase. ${ }^{[52]}$ Also, the dipole associated with the organic cations could participate in the polaronic transport, ${ }^{[57-58]}$ for example, by forming the polarization cloud around the charge carriers (in addition to the coupling between carrier and $\mathrm{PbI}_{6}$ network). ${ }^{[56]}$

The rather modest mobility of MHPs could present a significant hurdle in the development of high-performance transistors since high charge carrier mobilities are typically required for circuit applications. However, for solar cell applications, it has been reported that carrier lifetimes in MHPs are unusually long (particularly for direct gap semiconductors), ${ }^{[25]}$ 
Adv. Mater. 2017, DOI: 10.1002/adma.201702838

giving rise to long carrier diffusion lengths and consequently to the highly efficient collection of photoexcited charges and record-breaking PCE. ${ }^{[12,35,63]}$ One main contributing factor for these excellent attributes is the defect tolerance of MHPs, i.e., their charge transport is not significantly deteriorated by defects even in solution-processed films. ${ }^{[33-34,41,64-66]}$ Considering $\mathrm{MAPbI}_{3}$ as an example, the dominant defects are the donor interstitial MA $\left(\mathrm{MA}_{\mathrm{i}}\right)$ and the acceptor $\mathrm{Pb}$ vacancy $(\mathrm{V} \mathrm{Pb})$, both of which have low formation energies and may contribute to the observed ambipolar conductivity. ${ }^{[41]}$ Self-compensation also does not appear to be a limiting issue for either p-type or n-type doping as the Fermi level pinning points (related to the doping concentration beyond which further doping is compensated) are close to the band edges, suggesting that appreciable doping level is possible. Furthermore, the defect tolerance manifests itself in the shallow energy levels (close to the band edges or even within the bands) of defects with low formation energies. Other defects that lead to states deep in the band gap, creating the Shockley-Read-Hall (SRH) non-radiative recombination centers, have high formation energies and are not likely to be present. ${ }^{[33,41,67]}$ Consequently, the thermodynamically favorable defects are not detrimental to the photovoltaic performance of $\mathrm{MAPbI}_{3}$. This may be reflected in the long carrier lifetimes and long diffusion lengths as mentioned previously. The defect tolerating properties of MHPs arise from their unique band structures and could potentially provide a new direction for developing materials with "immune" charge transport properties. ${ }^{[65-66]}$

The low formation energies of defects may also contribute to the ion migration in $\mathrm{MAPbI}_{3}$ (Figure 1g) via vacancy diffusion that leads to the observed significant ionic transport. ${ }^{[36,68]}$ The diffusion of ions is also a leading explanation for peculiar phenomena observed in MHPs such as the hysteresis, ${ }^{[69-70]}$ switchable photovoltaic effect, ${ }^{[71]}$ large dielectric constant at low frequencies, ${ }^{[46]}$ and slow photoconductivity response. ${ }^{[72]}$ The process of ion migration is currently believed to be the main reasons that limits the application of MHPs in high mobility field-effect transistor since diffusion and accumulation of mobile ions in the 
Adv. Mater. 2017, DOI: 10.1002/adma.201702838

channel will tend to screen the applied gate field resulting to the often observed poor channel current modulation and significant current-voltage hysteresis. ${ }^{[73]}$

\section{Perovskites Based Transistors and Their Applications for Optoelectronics}

\subsection{Two-dimensional layered perovskite transistors}

Despite the spectacular recent developments in the field of PSCs, there is only a handful of reports focusing on the charge-transport properties of MHPs studied using field-effect transistors. The primary reason for this is the difficulty in fabricating MHP transistors with reliable operating characteristics. This is not the case for all-inorganic perovskite material systems such as oxide perovskites for which high performance transistors and microelectronic circuits have already been demonstrated. ${ }^{[74-77]}$ Key to this is the ability to grow atomically flat oxide-oxide heterointerfaces that promote the formation of a two-dimensional electron gas (2DEG) which in turn leads to extremely high charge carrier mobility. ${ }^{[74]}$ Field-effect transistors based on such low-dimensional perovskite heterojunction channels are found to exhibit not only high charge carrier mobility but also a variety of exotic physical phenomena ${ }^{[78]}$ including; interface superconductivity, ${ }^{[79]}$ and strong spin-orbit coupling, ${ }^{[80]}$ which in turn have led to the development of new device concepts.

Unlike oxide perovskites, however, the conductivity of MHPs results from the extended framework composed of various inorganic elements held together via ionic interactions and organic ions located in the voids between the metal-halide octahedral acting as the scaffold. ${ }^{[33]}$ Reducing the dimensionality of layered MHPs from the 3D form (i.e. $A_{2} A^{\prime}{ }_{n-1} B_{n} X_{3 n+1}$ where $n$ $=\infty$ ) to a $2 \mathrm{D}$ form (i.e. $\mathrm{n}=1$ ), has been predicted to result to dramatic changes in electrical conductivity, i.e. transition from a metallic to a semiconducting state. ${ }^{[81]}$ Indeed, this approach has been exploited for the development of the first MHP-based thin-film transistors (TFTs) employing the $2 \mathrm{D}$ system $\left(\mathrm{C}_{6} \mathrm{H}_{5} \mathrm{C}_{2} \mathrm{H}_{4} \mathrm{NH}_{3}\right)_{2} \mathrm{SnI}_{4}$ (phenylethylammonium tin iodide or $\mathrm{PEASnI}_{4}$ ), rather than its $3 \mathrm{D}$ counterpart $\mathrm{CH}_{3} \mathrm{NH}_{3} \mathrm{SnI}_{3}{ }^{\left[{ }^{[82]}\right.}$ Resulting TFTs showed clear p-channel function 
Adv. Mater. 2017, DOI: 10.1002/adma.201702838

with hole mobility on the order of $\sim 0.5 \mathrm{~cm}^{2} \mathrm{~V}^{-1} \mathrm{~s}^{-1}$ (Figure 2a). Kagan et al. have also shown that even when spin-coated, highly-oriented MHP crystals could be grown exclusively in the $(0,0, l)$ direction hence favoring hole transport in the $2 \mathrm{D}$ crystal plane parallel to the transistor channel. ${ }^{[82]}$ Although these early results indicated potential for further TFT performance improvement, the hole mobility of PEASnI 4 TFTs $\left(\sim 0.5 \mathrm{~cm}^{2} \mathrm{~V}^{-1} \mathrm{~s}^{-1}\right)$ was significantly lower than the Hall mobility values of 50 and $2320 \mathrm{~cm}^{2} \mathrm{~V}^{-1} \mathrm{~s}^{-1}$ measured and calculated for pressed pellets and single crystals of $\mathrm{CH}_{3} \mathrm{NH}_{3} \mathrm{SnI}_{3}$, respectively, hence highlighting the need for additional work. ${ }^{[83-86]}$ Nevertheless, early work by Kagan et al., using solution-grown layers to achieve such electrical performance showed great promise for inexpensive, high-performing thin-film transistor with industrial perspective for large-area applications as other solutionprocessable materials, especially at that time, exhibited significantly lower transporting characteristics. $^{[87]}$

More recently Matsushima et al., reported the development of top-gate, top-contact (TG-TC) PEASnI 4 -based transistor with hole mobility of $15 \mathrm{~cm}^{2} \mathrm{~V}^{-1} \mathrm{~s}^{-1}$ using the fluoropolymer CYTOP (Asahi Glass) as the gate dielectric (Figure 2b and 2c). ${ }^{[88]}$ The improvement was attributed to the presence of a high-quality MHP layer formed on $\mathrm{NH}_{3} \mathrm{I}$ self-assembledmonolayer ( $\mathrm{SAM}$ )-treated $\mathrm{SiO}_{2}$ substrate. These findings suggest that the hole mobility value extracted from TFTs do not necessarily represent the fundamental transport limit for the particular MHP material studied, with the latter being determined, primarily, by extrinsic effects such as the stoichiometry and structural quality (defects, grain boundaries etc.) of the channel layer.

From the results presented and discussed so far it becomes clear that improving the operating characteristics of MHP transistors further would most certainly require the development of defect-free (single-crystal) MHP layers, ideally using inexpensive and highly scalable processing methodologies. A few different approaches could in principle be explored for achieving this objective including: (i) development of new materials with improved 
Adv. Mater. 2017, DOI: 10.1002/adma.201702838

composition and processing characteristics, and (ii) development of advanced processing techniques that enable reliable growth of high quality MHP layers onto large-area substrates. Understanding the chemical reactions, nucleation and crystal growth during materials processing is also expected to provide vital insights for efficient materials/formulation optimization, and ultimately improved device performance.

\subsection{Metal-halide perovskite transistors}

The first methylammonium lead halide $\left(\mathrm{MAPbI}_{3-\mathrm{x}} \mathrm{Cl}_{\mathrm{x}}\right)$ based TFT was demonstrated in a topgate bottom-contact (TG-BC) configuration by Mei et al. ${ }^{[89]}$ The Au source-drain (S-D) contacts were treated with the 2,3,5,6-tetrafluoro-4-(trifluoromethyl)benzenethiol (TTFB) selfassembled monolayer (SAM), while CYTOP was used as the gate dielectric. The resulting devices showed ambipolar transport characteristics with channel on-off current ratio in the range $10^{2}-10^{3}$. Hole transport appeared to be more prominent with an estimated mobility value of $1.3 \mathrm{~cm}^{2} \mathrm{~V}^{-1} \mathrm{~s}^{-1}$ as compared to that of $1 \mathrm{~cm}^{2} \mathrm{~V}^{-1} \mathrm{~s}^{-1}$ for electrons. Although encouraging, the non-ideal operating characteristics obtained did not allow for any detailed charge transport analysis to be performed. The latter was attributed to the instability of the devices which in some cases appeared to degrade even when stored under inert conditions (i.e. vacuum, nitrogen ambient). Shortly after, Wu et al. reported bottom-gate top-contact (BG-TC) transistors using $\mathrm{MAPbI}_{3}$ as the active channel and $\mathrm{SiO}_{2}$ and $\mathrm{Ag}$ as the gate dielectric and source-drain contacts, respectively. ${ }^{[90]}$ In the latter study, a series of transfer characteristics obtained at different drain voltages $\left(V_{D}\right)$ were recorded but with all TFTs now exhibiting unipolar n-channel character. The maximum electron mobility value extracted appeared to be very high and on the order of $566 \mathrm{~cm}^{2} / \mathrm{Vs}$ and was attributed to the superior intrinsic charge transport properties of $\mathrm{MAPbI}_{3}$. However, close examination of the current-voltage curves reveal significant deviations from ideal TFT operation, hence calling into question the applicability of gradual channel approximation model ${ }^{[48]}$ used for the mobility calculation. For example, the maximum channel 
Adv. Mater. 2017, DOI: 10.1002/adma.201702838

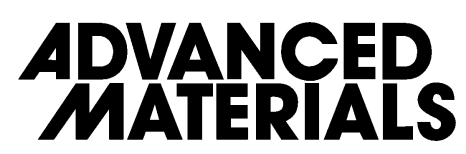

current measured at a gate voltage $\left(\mathrm{V}_{\mathrm{G}}\right)$ of $20 \mathrm{~V}$ for several different $\mathrm{V}_{\mathrm{D}},(0.1$ to $3 \mathrm{~V})$ appears to remain constant, or slightly reduced, with increasing $\mathrm{V}_{\mathrm{D}}$ and $\mathrm{V}_{\mathrm{G}}$. This unexpected behavior points to the existence of extrinsic charge transport processes such as ion diffusion/transport, which under certain circumstances may lead to erroneous mobility calculations since the apparent channel transconductance would be the result of the mixed charge transport character - a feature not accounted by the aforementioned transport model. Unfortunately, the authors did not report the reverse (return) $V_{G}$ sweeps making validation of such an assumption impossible. To this end, it is expected that ion diffusion within the channel to give rise to strongly hysteresis behaviour the direction of which (clockwise, anticlockwise), in combination with the impact of $\mathrm{V}_{\mathrm{G}}$ scan rate, could be used to study the ion movement in the channel. Irrespective of the actual charge transport mechanism, the results highlighted the issues associated with the analysis of the operating characteristics of MHP-based transistors.

The existence of ion-migration and the highly polarisable nature of MHPs are two well documented properties. ${ }^{[36,68,91]}$ In the case of MHP transistors, and in line with our previous discussion, such material characteristics are expected to lead to significant electric-field screening along the channel leading to anomalous device characteristics (operating hysteresis) which could, under certain circumstances, lead to erroneous results, and hence conclusions. Labram et al. observed no field effect induced in a $\mathrm{MAPbI}_{3}$ based field-effect transistor when the devices were characterized at temperatures $>215 \mathrm{~K}$ (Figure 2d). ${ }^{[73]}$ The effect was attributed to the existence of temperature-activated polarization effects taking place at grain boundaries within the polycrystalline $\mathrm{MAPbI}_{3}$ layer. The polarization effect was attributed to the diffusion of ionic species which tends to become more mobile at higher temperatures. The process was further investigated by monitoring the transient channel current behavior of $\mathrm{MAPbI}_{3}$ transistors through the application of a pulsed $V_{G}$ potential at a constant $V_{D}$ (Figure 2e). ${ }^{[73]}$ By performing the same measurements, but with the device now maintained at different temperatures $(T)$ in the range $150-220 \mathrm{~K}$, the team was able to extract the $\mathrm{I}_{\mathrm{D}}$ decay as a function of $T$ (Figure $\mathbf{2 f}$ ). 
Adv. Mater. 2017, DOI: 10.1002/adma.201702838

The obtained results revealed significantly lower decay times for TFTs maintained at low $T$, and was attributed to the slower gate field neutralization process due to slower ion movement in the channel. By extending the $T$-dependence studies to $\mathrm{MAPbI}_{3}$ solar cells, the same team showed that the cell's PCE also degraded with decreasing temperature primarily due to the reduction in the short-circuit current $\left(\mathrm{J}_{\mathrm{sc}}\right) .{ }^{[73]}$ It was argued that a higher rate of charge recombination at lower temperatures is likely responsible for this observation as slow ionic movement could potentially cause reduction in internal electric field, hence reducing the carrier collection efficiency. ${ }^{[68]}$ The pioneering study by Labram et al. ${ }^{[73]}$ highlighted the dramatic role that mobile ionic species play in the operating characteristics of MHP devices and particularly field-effect transistors.

Future utilization of $\mathrm{MAPbI}_{3}$ TFTs in any practical applications would require the development of devices that are able to operate robustly across a wide temperature range, including room-temperature. To this end, recently Senanayak et al. studied the impact of layer microstructure on the operating characteristics in $\mathrm{MAPbI}_{3}$ transistors. ${ }^{[92]}$ The team was able to demonstrate transistors with electron mobility of $0.5 \mathrm{~cm}^{2} \mathrm{~V}^{-1} \mathrm{~s}^{-1}$, although with noticeable hysteresis, that are able to operate at room-temperature. It was shown that deposition of precursor solutions with different molar concentrations produced layers with significantly different morphologies. For example, $\mathrm{MAPbI}_{3}$ layers processed from higher molar concentration formulations comprised of larger grains with the resulting devices showing improved on-off channel current modulation and lower hysteresis as compared to $\mathrm{MAPbI}_{3}$ transistors processed from less concentrated solutions. The authors attributed the improvements to a combination of factors including minimization of charged point defects (e.g. unconverted $\mathrm{PbI}_{2}$ ) located at the grain boundaries and a decrease in the polarization fluctuation of the $\mathrm{MA}^{+}$ cations with increasing grain size. In the same study, ${ }^{[92]}$ the authors have also showed that the surface energies of the S-D contacts and gate dielectric surfaces also play important roles on transistor operation. Optimum transistor performance was achieved through the use of 
Adv. Mater. 2017, DOI: 10.1002/adma.201702838

appropriate work function and surface energy modifying agents namely pentafluorobenzenethiol (PFBT) and polyethylenimine ethoxylated (PEIE), respectively (Figure 2g and $\mathbf{2 h}$ ). A significant improvement of electron transport was observed for PEIE and, surprisingly, PFBT-treated $\mathrm{MAPbI}_{3}$ transistors as well. Although PEIE is known to enhance the electron injection in various n-type semiconductor materials due to barrier height lowering, PFBT is expected to have the opposite effect as it is often employed to improve hole injection in organic semiconductor devices by increasing the work function of common holeinjecting electrodes such as Au. ${ }^{[93-94]}$ The observed performance improvement was attributed to a combination of enhanced carrier injection and favorable $\mathrm{MAPbI}_{3}$ layer morphology due to PEIE-/PFBT-treatment.

In addition to transistor measurements, Senanayak et al. also used the dielectric loss spectroscopy technique to study the ion movement within the $\mathrm{MAPbI}_{3}$ layer. Obtained results revealed that ion migration occurs at around $240 \mathrm{~K}$ (Figure 2i), which is slightly higher than the $210 \mathrm{~K}$ reported by Labram et al. ${ }^{[73]}$ The relatively small difference is most likely attributed to the different device configurations, substrates and precursor materials employed. Although Senanayak et al. have not observed any p-type/ambipolar transport in of $\mathrm{MAPbI}_{3}$, their work provided valuable insight into the inner workings of the $\mathrm{MAPbI}_{3}$ transistors and the important factors governing charge transport within the active channel. ${ }^{[92]}$

A significant drawback associated with $\mathrm{MAPbI}_{3}$ is its poor thermal stability. ${ }^{[95]}$ To address this bottleneck several recent studies have focused on the use of mixed cations involving organic cations, such as formamidinium (FA) and methylammonium, as well as inorganics such as caesium (Cs) and rubidium $(\mathrm{Rb}) .{ }^{[96]}$ Although relatively simple, the approach has been shown to improve the structural stability of black-phase perovskites. ${ }^{[96]}$ Yusoff et al. developed a series of triple-cation $\mathrm{Cs}_{\mathrm{x}}\left(\mathrm{MA}_{0.17} \mathrm{FA}_{0.83}\right)_{1-\mathrm{x}} \mathrm{Pb}\left(\mathrm{Br}_{0.17} \mathrm{I}_{0.83}\right)_{3}$ based perovskite transistors with an optimized Cs composition of $\mathrm{x}=0.15{ }^{[97]}$ Resulting devices exhibited balanced hole and electron transport with mobility values on the order of $2 \mathrm{~cm}^{2} \mathrm{~V}^{-1} \mathrm{~s}^{-1}$. ${ }^{\text {[97] }}$ 
Adv. Mater. 2017, DOI: 10.1002/adma.201702838

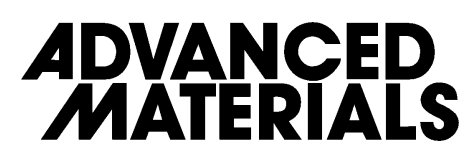

Interestingly, triple-cation MHP-based transistors where $\mathrm{x}$ for $\mathrm{Cs}_{\mathrm{x}}$ ranges from 0 to 0.35 (except for 0.15 ) could be operated in either unipolar ( $\mathrm{n}$ - or $\mathrm{p}$-channel) or ambipolar modes. Although in the linear operating regime $\left(V_{G}>>V_{D}\right)$ the devices yield appreciable on-off ratio values of $\sim 10^{4}$, the latter was found to reduce to $\sim 10$ when transistors were operated in saturation $\left(\mathrm{V}_{\mathrm{G}}-\right.$ $\mathrm{V}_{\mathrm{T}} \approx \mathrm{V}_{\mathrm{D}}$, where $\mathrm{V}_{\mathrm{T}}$ is the threshold voltage). This is not surprising for ambipolar TFTs since, under certain biasing regimes, ${ }^{[98-99]}$ holes and electrons may co-exist in the channel leading to a large off-current. Understanding the origin for the supressed $\mathrm{I}_{\mathrm{D}(\text { off })}$ in transistors where for $\mathrm{Cs}_{\mathrm{x}}$ the $\mathrm{x}=0.15$, is very important and should be investigated further. Finally, the work by Yusoff et al. was the first to demonstrate the possibility of using MHP materials for realizing not only discrete ambipolar transistors but also the first MHP transistor-based complementary-like logic inverters with an appreciable signal gain of $>20 .{ }^{[97]}$

\subsection{Perovskite phototransistors and light-emitting transistors}

Another area where MHP materials have shown great promise is that of optoelectronic devices including, optically-pumped lasers, ${ }^{[100]}$ light-emitting diodes, ${ }^{[101-102]}$ photodetectors ${ }^{[103]}$ and Xray detector. ${ }^{[104-105]}$ Recent attempts to integrate optoelectronic functionality with active electronic components resulted to the development of perovskite phototransistors and light emitting transistors. ${ }^{[106-110]} \mathrm{Li}$ et al. developed and studied ambipolar $\mathrm{MAPbI}_{3}$-based phototransistors and demonstrated the ability of these devices to detect light. ${ }^{[106]}$ When measured in the dark and under white-light illumination at $10 \mathrm{~mW} \mathrm{~cm}^{-2}$ (Figure 3a), ${ }^{[106]}$ a maximum photoresponsivity of $320 \mathrm{~A} \mathrm{~W}^{-1}$ was obtained with the devices exhibiting high photoinduced channel current modulation $\left(>10^{5}\right)$ (Figure 3b). Importantly, the phototransistors exhibited excellent photo-switching response with rise and decay times (measured by exposing the devices to short optical pulses) of 6.5 and $5 \mu$ s, respectively (Figure 3c), suggesting that device operation is due to photogenerated carriers rather than ion diffusion. ${ }^{[106]}$ In addition to $\mathrm{MAPbI}_{3}$-based transistors, Li et al., have also demonstrated devices based on $\mathrm{MAPbI}_{3-\mathrm{x}} \mathrm{Cl}_{\mathrm{x}}{ }^{[106]}$ 
Adv. Mater. 2017, DOI: 10.1002/adma.201702838

Although the latter devices exhibited enhanced transport characteristics with significantly higher carrier mobilities, a lower photoresponsivity value of $\sim 47 \mathrm{~A} \mathrm{~W}^{-1}$ (meausred at $\mathrm{V}_{\mathrm{G}}=-40$ V), was obtained. The result was attributed to the increased channel off-current, a common feature seen in those devices. The enhanced carrier mobility, on the other hand, was attributed to the improved $\mathrm{MAPbI}_{3-\mathrm{x}} \mathrm{Cl}_{\mathrm{x}}$ layer morphology as compared to $\mathrm{MAPbI}_{3}$ films measured by atomic force microscopic (AFM), highlighting the significant role of grain boundaries on the device's photoresponse. A further significant finding is the fact that $\mathrm{MAPbI}_{3}$ transistors continued to operate with minor hysteresis even at room temperature (Figure $\mathbf{3 b}$ ). These findings contrast those reported by Labram et al., ${ }^{[73]}$ for the same material system where no transistor operation could be observed at or above room temperature due gate-field screening by mobile ions. A possible reason for this starkly contrasting observations could be the differences in the microstructure and stoichiometry of the $\mathrm{MAPbI}_{3}$ layers employed. To this end, the characteristic diffraction peak at $12.65^{\circ}$ reported for $\mathrm{MAPbI}_{3}$ layers and is assigned to unconverted $\mathrm{PbI}_{2},{ }^{\left[{ }^{[92]}\right.}$ was completely absent from the diffractogram reported by Li et al., ${ }^{[106]}$ hence supporting the idea of the existence of layers with improved stoichiometry.

Light-emitting transistors (LETs) ${ }^{[111-113]}$ based on MHP materials is another type of bifunctional device developed in recent years. Unlike conventional light-emitting diodes, LETs are characterized by a narrow and well defined active area that makes them attractive for applications in the areas of high-definition optical displays, optical communications and, potentially, electrically-pumped lasers. ${ }^{[113]}$ In the case of other well-established LETs technologies, such as those based on organic semiconductors, device operation relies on the use of ambipolar light-emitting polymers such as poly(9,9-di- $n$-octylfluorene-alt-benzothiadiazole) (F8BT) and $\quad \operatorname{poly}((9,9-$ dioctylfluorene)-2,7-diyl-alt-[4,7-bis(3-hexylthien-5-yl)-2,1,3benzothiadiazole]-2',2-diyl) (F8T2T) as the active channel material. ${ }^{[113-114]}$ The ambipolar nature of these materials promotes efficient hole-electron recombination within the channel in a highly controllable manner via the application of a gate field. In the case of MHP materials, 
Adv. Mater. 2017, DOI: 10.1002/adma.201702838

their often observed ambipolar character combined with the high photoluminescence quantum yield, ${ }^{[115]}$ makes them excellent candidates for application in LETs.

In 2015 Chin et al. reported the first MHP-based LETs using $\mathrm{MAPbI}_{3}$ as the active channel material. ${ }^{[108]}$ Pre-patterned bottom-gate, bottom contact transistor structures (Figure 3d) were combined with $\mathrm{MAPbI}_{3}$ layers deposited last to reduce potential environmental impact and prevent unwanted degradation from subsequent fabrication steps. Similar to the findings reported by Lebram et al. and Senanayak et al. , $^{[73,92]}$ the authors observed reverse temperatureactivated channel current modulation behaviour, indicative of ion diffusion, but with the addition of light emission from within the transistor channel when operated in saturation at temperatures in the range 78-178 $\mathrm{K}$ (Figure 3e). Interestingly, the maximum temperature at which light-emission could be observed (i.e. $178 \mathrm{~K}$ ), was found to be slightly lower than that required for transistor operation $(\sim 198 \mathrm{~K}) \cdot{ }^{[108]}$ A plausible reason for this surprising observation might be the weak n-channel accumulation observed for the LETs at $198 \mathrm{~K}\left(\mathrm{~V}_{\mathrm{G}}=\mathrm{V}_{\mathrm{D}}=100 \mathrm{~V}\right)$. A further interesting observation is that Peaks 1 and 3 in the EL spectra in Figure 3e, were only

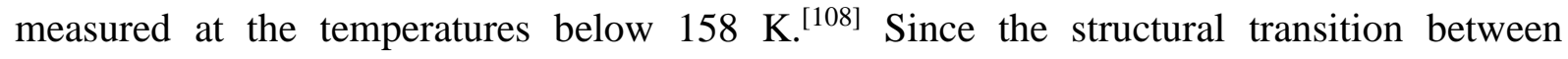
tetragonal and orthorhombic phases in $\mathrm{MAPbI}_{3}$ were reported to occur at a similar temperature, ${ }^{[38]}$ the authors reported that Peaks 1 and 3 could be attributed to the bound exciton present in the orthorhombic phase which exists only at low temperatures. On the other hand, Peak 2 might reflect the free excitons existing in the high-temperature tetragonal phase. Finally, the light emission (recombination) region and corresponding intensity in these transistors were both found to be $V_{G}$ and $V_{D}$ dependent as seen in Figure 3f. ${ }^{[108]}$ This is not a surprising as it closely resembles the operating characteristics of organic semiconductor based LETs. ${ }^{[13,116]}$

\section{Opportunities and Challenges}

\subsection{Manufacturing towards large-area applications}


Adv. Mater. 2017, DOI: 10.1002/adma.201702838

At present spin-casting remains the most popular solution-based processing route for the deposition of MHP thin-films. ${ }^{[32]}$ This is because the method can deliver relatively uniform layers suitable for small area devices (typically $<1 \mathrm{~cm}^{2}$ ). However, processing protocols and deposition techniques other than spin-casting techniques are urgently needed especially for the exploitation of MHPs in commercial applications where truly large area processing would be required. To this end, the relevant scientific community has devoted considerable effort in developing several large-volume high-throughput manufacturing methods, such as blade coating, ${ }^{[117]}$ slot die coating, ${ }^{[118]}$ spray coating, ${ }^{[119]}$ and screen printing, ${ }^{[120]}$ to fulfil future industrial needs. The unprecedented and rapid advances achieved in recent years in the area of photovoltaics could also accelerate the development of industrial-scale production methods that are also compatible with MHP-based transistor/electronics manufacturing, hence shortening the time required for commercial exploitation. However, the fundamental differences in device operation and architecture between a transistor and a photovoltaic cell would most certainly require radically different processing protocols and potentially deposition methods to be developed. A good example is from the discussion in Section 3, where the same type of MHP material that has been processed under slightly different conditions was reported to yield significantly different charge transport characteristics when tested in field-effect transistors. ${ }^{[90 \text {, }}$ 92, 106] The latter is particularly important for successful implementation of MHPs in electronic applications as the ability to manipulate the type of majority carriers is essential for the design and implementation of complex microelectronic circuitry. On the other hand, the sensitivity of MHPs to processing conditions could be exploited to control the crystallization and growth kinetics during deposition, and hence the overall quality of the layers and performance of resulting devices. ${ }^{[73,89,92,97]}$

From the discussion thus far it is clear that development of large-area MHP-based microelectronics will most certainly require significant strides towards better understanding of perovskite film formation and the development of reliable manufacturing protocols. Meanwhile, 
Adv. Mater. 2017, DOI: 10.1002/adma.201702838

the identification of a suitable transistor architecture and optimized substrate, and/or contact, treatment could both play crucial roles in this regard. To this end, Senanayak et al. ${ }^{[92]}$ showed that different substrate treatments could lead to different sizes of perovskite crystallites, hence significantly influencing the transporting properties, while Matsushima et al., showed the benefits of using a top-gate transistor architecture combined with a low-k fluoropolymer as the gate dielectric. ${ }^{[88]}$

\subsection{Operational, environmental, and long-term stability}

Despite the fact that high-efficiency PSC has been achieved, the PSC research community has expressed considerable concerns regarding the instability of MHP-based materials that could potentially hinder commercial exploitation of PSCs. ${ }^{[121-123]}$ Numerous factors that could cause performance degradation in PSC, such as moisture, oxygen, temperature, light and electric field, have been identified. ${ }^{[124]}$ In a recent comment on PSC stability by Yang Yang and Jingbi $\mathrm{You}^{[123]}$, five strategies have been proposed to improve the stability of PSCs, including:

1) Modifying $\mathrm{ABX}_{3}$ with more stable elements in $\mathrm{A}, \mathrm{B}$ and $\mathrm{X}$ sites. ${ }^{[125-126]}$

2) Improving film qualities, such as crystallites sizes and smoothness. ${ }^{[127]}$

3) Engineering thermally-stable, water repelling interlayers, charge-transporting layers. ${ }^{[128]}$

4) Minimizing the exposure to environment by encapsulation techniques. ${ }^{[129]}$

5) Exotic crystal design. ${ }^{[123,130]}$

However, it needs to be stressed here that unlike PSCs where the PV modules are usually operated in outdoor environment, most microelectronic-based products are not. Rather, such devices would be more likely subjected to unintentional heating/cooling during operation, which also represents a major challenge. For example, $\mathrm{MAPbI}_{3-\mathrm{x}} \mathrm{Cl}_{\mathrm{x}}$, one of the most studied MHPs, is not thermally stable as it tends to decompose at $\sim 85^{\circ} \mathrm{C} \cdot{ }^{[95]}$ Furthermore, the density of defect states in MHP materials could be affected during constant device operation causing dramatic changes in the electrical properties of the transistors and circuits. ${ }^{[41][29-30]}$ In an effort 
Adv. Mater. 2017, DOI: 10.1002/adma.201702838

to address the latter issue, Yusoff et al. ${ }^{[97]}$ have proposed the use of triple-cation based MHPs for transistors and logic gates, hence demonstrating the potential of their approach. In spite the substantial number of scientific and technological challenges, the simple chemistry and processing versatility of MHPs present great opportunities for the microelectronics research community that can't be overlooked. To this end, the current upsurge of MHP research could indeed benefit the field of large-area electronics and pave the way to future developments.

\subsection{Health and environmental concerns}

One of the main disincentives to the development and implementation of MHP-based electronics (with PSCs as the current main focus) is the use of lead (Pb) which is the central component of the most successful MHPs. The heavy $\mathrm{Pb}$ atom is known for its toxicity, but attempts at substituting it with other elements such as $\mathrm{Sn}, \mathrm{Ge}, \mathrm{Bi}$, and $\mathrm{Sb}$ have not yet produced high-efficiency PSCs. ${ }^{[131]} \mathrm{Pb}$ is known for its deleteriously effects on the central nervous system, production of blood cells, reproductive system, and liver and kidney functions, leading to severe disorders and cancers. ${ }^{[132]}$ Currently, there is no safe level of lead exposure, ${ }^{[132-133]}$ but as for the occupational health and safety guidelines, the United States (US) limits the $\mathrm{Pb}$ air exposure to $50 \mu \mathrm{g} \mathrm{m}^{-3}$ ( $8 \mathrm{~h}$ time-weighted average) while the European Union (EU) and United Kingdom (UK) set a higher limit of $150 \mu \mathrm{g} \mathrm{m}^{-3}$ (8h time-weighted average). ${ }^{[134]}$

With the serious concern on the negative health effects of $\mathrm{Pb}$, publications specifically focusing on the toxicity of MHPs have begun to appear. Benmessaoud et al. ${ }^{[135]}$ studied the cytotoxicity of $\mathrm{MAPbI}_{3}$ by feeding human and mice cells with culture media containing dissolved perovskite. Babayigit et al. ${ }^{[136]}$ investigated the toxicity of $\mathrm{Pb}$ - and $\mathrm{Sn}$-based perovskites in zebrafish by adding $\mathrm{PbI}_{2}$ and $\mathrm{SnI}_{2}$, which are the degradation products of perovskites from reaction with water or humidity (the anticipated pollutants from perovskite solar panels), to the aquatic environment containing zebrafish embryos. These reports showed lethality and harmful effects of Pb-based MHPs on cellular and organism levels. Surprisingly, 
Adv. Mater. 2017, DOI: 10.1002/adma.201702838

the latter work also showed that Sn-based MHPs could also be harmful as in their test $\mathrm{SnI}_{2}$ decomposed further and released HI, greatly acidifying the environment. This raises the question on the research into Sn-based MHPs with the hope to find a more environmentally friendly perovskite compounds.

Looking at a larger environmental impact of PSC industrialization, several groups have carried out the life cycle assessments (LCAs) that include materials sourcing, solar panel fabrication, operation, and decommissioning. The LCAs covered not only ecotoxicity and human toxicity but also wider impacts such as climate change, eutrophication, land use, and resource depletion among others. ${ }^{[137-140]}$ Generally, it is found that $\mathrm{Pb}$ has a smaller impact compared to other substances or processes involved in the cycle such as the use of energy, precious metals, solvents, or even other components of the perovskite layer. Environmental impacts can be closely managed during the sourcing, fabricating, and recycling or decommissioning steps by strictly adhering to high health and safety standards and environmental protection guidelines. During operation, extra safety measures may have to be included to contain material leakage in the case of mechanical failure for example by using effective encapsulation. ${ }^{[133,141]}$

Although the MHP-based electronics is still in the early development stage, lessons learned from PSCs will likely provide effective guidelines for managing the health and environmental impacts. In fact, the use of the perovskite materials themselves is supposedly less than in the case of PSCs because the active electronic parts do not require a large amount of material compared to the light absorbing layer in solar cells. The danger of $\mathrm{Pb}$ should not be overlooked, however, and while industrial production can be tightly regulated, concerns should also be placed on the lab-scale research. Experiments always involve new materials and processes and sometimes take place in labs which are not specialized in handling toxic compounds. As mentioned earlier, there is no safe level of $\mathrm{Pb}$ exposure. 
Adv. Mater. 2017, DOI: 10.1002/adma.201702838

\section{Conclusions}

We have presented an overview of the background knowledge on the crystal structure, electronic properties and charge transport behavior of MHPs and their applications in the area of field-effect transistors. Despite the highly dispersive nature of the bands and the small effective masses for holes and electrons in many MHP materials, the reported carrier mobilities are still significantly lower than the predicted values, suggesting that dynamic disorder amongst other extrinsic effects, play a dominant role in long range transport. To this end, defect properties of MHPs, studies show that defects such as organic cations (e.g. $\mathrm{MA}_{\mathrm{i}}$ in $\mathrm{MAPbI}_{3}$ ) and $\mathrm{V}_{\mathrm{Pb}}$ have low formation energies and could indeed contribute to the often observed ambipolar conductivity. Moreover, they form shallow defect energy levels which appear not to be detrimental for the solar cell performance. This flexible defect nature may also be the cause for the often-observed ionic conduction in MHPs and represents a significant hurdle for application in field-effect transistors and microelectronic circuits.

Despite these issues, recent developments in the area of MHP-based transistors demonstrate the potential of the technology for application in large-area optoelectronics. This effort has been motivated primarily by the attractive properties of MHPs that include; ultimate processing versatility, which could translate to cost-effective manufacturing via large-area processing; their often simple and flexible chemistry; and the prospects for superior charge transport. We are now at a stage where MHP transistors are being fabricated in different laboratories around the world and the first logic gates being demonstrated. In terms of charge carrier mobility, MHP transistors have, in some cases, outperformed various established technologies such as those based on amorphous-Si and various organic semiconductors, and are fast approaching those of amorphous metal oxide-based TFTs.

The combination of processing versatility and promising charge carrier transport with the extraordinary optoelectronic properties of MHPs, has also enabled the development of bifunctional devices. Among these, MHP-based light-sensing and light-emitting transistors 
Adv. Mater. 2017, DOI: 10.1002/adma.201702838

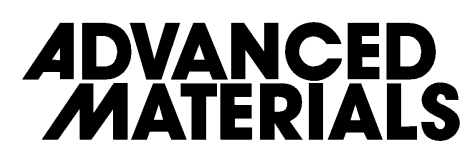

represent two of the most interesting device concepts. Although these types of devices are still in the early stage of development, the potential for further technological applications clearly remains substantial.

Further research effort in understanding the structure-property relationship in MHP materials is now urgently needed as it would lead to MHP materials with improved physical characteristics. Such developments would help to expand the application space of MHPs well beyond the energy sector and create new avenues of materials and solid-state device research.

\section{Acknowledgements}

Y.-H. L. and P. P. contributed equally to this work.

Received: ((will be filled in by the editorial staff))

Revised: ((will be filled in by the editorial staff)) Published online: ((will be filled in by the editorial staff))

\section{Reference}

[1] X. Zou, Y. Zhang, Chem. Soc. Rev. 2015, 44, 5148-5180.

[2] W. Li, J. Liu, D. Zhao, Nat. Rev. Mater. 2016, 1, 16023.

[3] T. Hisatomi, J. Kubota, K. Domen, Chem. Soc. Rev. 2014, 43, 7520-7535.

[4] D. Larcher, J. M. Tarascon, Nat. Chem. 2015, 7, 19-29.

[5] S. Berardi, S. Drouet, L. Francas, C. Gimbert-Surinach, M. Guttentag, C. Richmond, T. Stoll, A. Llobet, Chem. Soc. Rev. 2014, 43, 7501-7519.

[6] F. Bonaccorso, L. Colombo, G. Yu, M. Stoller, V. Tozzini, A. C. Ferrari, R. S. Ruoff, V. Pellegrini, Science 2015, 347, 1246501.

[7] M. A. Green, A. Ho-Baillie, H. J. Snaith, Nat. Photon. 2014, 8, 506-514.

[8] L. Lu, T. Zheng, Q. Wu, A. M. Schneider, D. Zhao, L. Yu, Chem. Rev. 2015, 115, 12666-12731.

[9] M. Urbani, M. Grätzel, M. K. Nazeeruddin, T. Torres, Chem. Rev. 2014, 114, 1233012396.

[10] G. H. Carey, A. L. Abdelhady, Z. Ning, S. M. Thon, O. M. Bakr, E. H. Sargent, Chem. Rev. 2015, 115, 12732-12763. 
Adv. Mater. 2017, DOI: 10.1002/adma.201702838

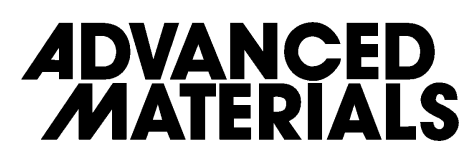

[11] H. S. Kim, C. R. Lee, J. H. Im, K. B. Lee, T. Moehl, A. Marchioro, S. J. Moon, R. Humphry-Baker, J. H. Yum, J. E. Moser, M. Gratzel, N. G. Park, Sci. Rep. 2012, 2, 591.

[12] S. D. Stranks, G. E. Eperon, G. Grancini, C. Menelaou, M. J. P. Alcocer, T. Leijtens, L. M. Herz, A. Petrozza, H. J. Snaith, Science 2013, 342, 341-344.

[13] D. Shi, V. Adinolfi, R. Comin, M. Yuan, E. Alarousu, A. Buin, Y. Chen, S. Hoogland, A. Rothenberger, K. Katsiev, Y. Losovyj, X. Zhang, P. A. Dowben, O. F. Mohammed, E. H. Sargent, O. M. Bakr, Science 2015, 347, 519.

[14] M. Saliba, T. Matsui, K. Domanski, J. Y. Seo, A. Ummadisingu, S. M. Zakeeruddin, J. P. Correa-Baena, W. R. Tress, A. Abate, A. Hagfeldt, M. Gratzel, Science 2016, 354, 206-209.

[15] A. Kojima, K. Teshima, Y. Shirai, T. Miyasaka, J. Am. Chem. Soc. 2009, 131, 60506051 .

[16] X. Li, D. Bi, C. Yi, J.-D. Décoppet, J. Luo, S. M. Zakeeruddin, A. Hagfeldt, M. Grätzel, Science 2016, 353, 58-62.

[17] M. M. Lee, J. Teuscher, T. Miyasaka, T. N. Murakami, H. J. Snaith, Science 2012, $338,643-647$.

[18] M. Liu, M. B. Johnston, H. J. Snaith, Nature 2013, 501, 395-398.

[19] O. Malinkiewicz, A. Yella, Y. H. Lee, G. M. Espallargas, M. Graetzel, M. K. Nazeeruddin, H. J. Bolink, Nat. Photon. 2014, 8, 128-132.

[20] J. M. Ball, M. M. Lee, A. Hey, H. J. Snaith, Energy. Environ. Sci. 2013, 6, 1739-1743.

[21] R. F. Service, Science 2016, 354, 1214.

[22] B. Saparov, D. B. Mitzi, Chem. Rev. 2016, 116, 4558-4596.

[23] P. Gómez-Romero, C. Sanchez, Functional Hybrid Materials, Wiley, 2004.

[24] G. Giorgi, J.-I. Fujisawa, H. Segawa, K. Yamashita, J. Phys. Chem. Lett. 2013, 4, 4213-4216.

[25] C. Wehrenfennig, G. E. Eperon, M. B. Johnston, H. J. Snaith, L. M. Herz, Adv. Mater. 2014, 26, 1584-1589.

[26] C. S. Ponseca, T. J. Savenije, M. Abdellah, K. Zheng, A. Yartsev, T. Pascher, T. Harlang, P. Chabera, T. Pullerits, A. Stepanov, J.-P. Wolf, V. Sundström, J. Am. Chem. Soc. 2014, 136, 5189-5192.

[27] T. Leijtens, S. D. Stranks, G. E. Eperon, R. Lindblad, E. M. J. Johansson, I. J. McPherson, H. Rensmo, J. M. Ball, M. M. Lee, H. J. Snaith, ACS Nano 2014, 8, 7147 7155 . 
Adv. Mater. 2017, DOI: 10.1002/adma.201702838

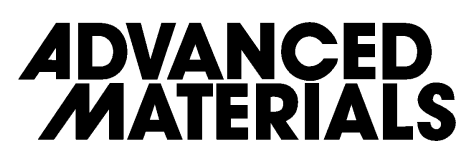

[28] Y. Chen, J. Peng, D. Su, X. Chen, Z. Liang, ACS Appl. Mater. Interfaces 2015, 7, 4471-4475.

[29] E. J. Yoo, M. Lyu, J.-H. Yun, C. J. Kang, Y. J. Choi, L. Wang, Adv. Mater. 2015, 27, 6170-6175.

[30] C. Gu, J.-S. Lee, ACS Nano 2016, 10, 5413-5418.

[31] S. D. Stranks, H. J. Snaith, Nat. Nano. 2015, 10, 391-402.

[32] S. Razza, S. Castro-Hermosa, A. D. Carlo, T. M. Brown, APL Mater. 2016, 4, 091508.

[33] T. M. Brenner, D. A. Egger, L. Kronik, G. Hodes, D. Cahen, Nat. Rev. Mater. 2016, 1, 15007.

[34] W.-J. Yin, J.-H. Yang, J. Kang, Y. Yan, S.-H. Wei, J. Mater. Chem. A 2015, 3, 89268942.

[35] M. B. Johnston, L. M. Herz, Acc. Chem. Res. 2016, 49, 146-154.

[36] Y. Yuan, J. Huang, Acc. Chem. Res. 2016, 49, 286-293.

[37] C. Li, X. Lu, W. Ding, L. Feng, Y. Gao, Z. Guo, Acta Crystallogr. Sect. B 2008, 64, 702-707.

[38] M. T. Weller, O. J. Weber, P. F. Henry, A. M. Di Pumpo, T. C. Hansen, Chem. Commun. 2015, 51, 4180-4183.

[39] T. Baikie, Y. Fang, J. M. Kadro, M. Schreyer, F. Wei, S. G. Mhaisalkar, M. Graetzel, T. J. White, J. Mater. Chem. A 2013, 1, 5628-5641.

[40] W.-J. Yin, T. Shi, Y. Yan, Adv. Mater. 2014, 26, 4653-4658.

[41] W. J. Yin, T. T. Shi, Y. F. Yan, Appl. Phys. Lett. 2014, 104, 063903.

[42] T. Umebayashi, K. Asai, T. Kondo, A. Nakao, Phys. Rev. B 2003, 67, 155405.

[43] S. Collavini, S. F. Völker, J. L. Delgado, Angew. Chem. Int. Ed. 2015, 54, 9757-9759.

[44] A. Miyata, A. Mitioglu, P. Plochocka, O. Portugall, J. T.-W. Wang, S. D. Stranks, H. J. Snaith, R. J. Nicholas, Nat. Phys. 2015, 11, 582-587.

[45] Q. Lin, A. Armin, R. C. R. Nagiri, P. L. Burn, P. Meredith, Nat. Photon. 2015, 9, 106112.

[46] E. J. Juarez-Perez, R. S. Sanchez, L. Badia, G. Garcia-Belmonte, Y. S. Kang, I. MoraSero, J. Bisquert, J. Phys. Chem. Lett. 2014, 5, 2390-2394.

[47] Q. Lin, A. Armin, P. L. Burn, P. Meredith, Acc. Chem. Res. 2016, 49, 545-553.

[48] S. M. Sze, K. K. Ng, Physics of semiconductor devices, John wiley \& sons, 2006.

[49] F. Brivio, K. T. Butler, A. Walsh, M. van Schilfgaarde, Phys. Rev. B 2014, 89, 155204.

[50] H. J. Snaith, J. Phys. Chem. Lett. 2013, 4, 3623-3630. 
Adv. Mater. 2017, DOI: 10.1002/adma.201702838

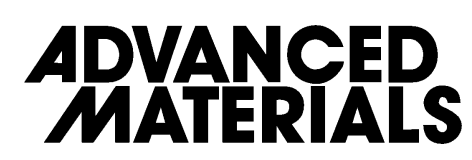

[51] T. M. Brenner, D. A. Egger, A. M. Rappe, L. Kronik, G. Hodes, D. Cahen, J. Phys. Chem. Lett. 2015, 6, 4754-4757.

[52] H. T. Yi, X. Wu, X. Zhu, V. Podzorov, Adv. Mater. 2016, 28, 6509-6514.

[53] M. Karakus, S. A. Jensen, F. D’Angelo, D. Turchinovich, M. Bonn, E. Cánovas, J. Phys. Chem. Lett. 2015, 6, 4991-4996.

[54] J. Feng, APL Mater. 2014, 2, 081801.

[55] Y. Rakita, S. R. Cohen, N. K. Kedem, G. Hodes, D. Cahen, MRS Commun. 2015, 5, 623-629.

[56] X. Y. Zhu, V. Podzorov, J. Phys. Chem. Lett. 2015, 6, 4758-4761.

[57] J. M. Frost, in arXiv, 2017, 1704.5404.

[58] M. Sendner, P. K. Nayak, D. A. Egger, S. Beck, C. Muller, B. Epding, W. Kowalsky, L. Kronik, H. J. Snaith, A. Pucci, R. Lovrincic, Mater. Horiz. 2016, 3, 613-620.

[59] D. A. Egger, A. M. Rappe, L. Kronik, Acc. Chem. Res. 2016, 49, 573-581.

[60] J. M. Frost, A. Walsh, Acc. Chem. Res. 2016, 49, 528-535.

[61] I. P. Swainson, C. Stock, S. F. Parker, L. Van Eijck, M. Russina, J. W. Taylor, Phys. Rev. B 2015, 92, 100303.

[62] C. Motta, F. El-Mellouhi, S. Kais, N. Tabet, F. Alharbi, S. Sanvito, Nat. Commun. 2015, 6, 7026 .

[63] G. Xing, N. Mathews, S. Sun, S. S. Lim, Y. M. Lam, M. Grätzel, S. Mhaisalkar, T. C. Sum, Science 2013, 342, 344-347.

[64] A. Walsh, D. O. Scanlon, S. Chen, X. G. Gong, S.-H. Wei, Angew. Chem. Int. Ed. 2015, 54, 1791-1794.

[65] A. Zakutayev, C. M. Caskey, A. N. Fioretti, D. S. Ginley, J. Vidal, V. Stevanovic, E. Tea, S. Lany, J. Phys. Chem. Lett. 2014, 5, 1117-1125.

[66] R. E. Brandt, V. Stevanović, D. S. Ginley, T. Buonassisi, MRS Commun. 2015, 5, 265275.

[67] M. H. Du, J. Mater. Chem. A 2014, 2, 9091-9098.

[68] C. Eames, J. M. Frost, P. R. F. Barnes, B. C. O’Regan, A. Walsh, M. S. Islam, Nat. Commun. 2015, 6, 7497.

[69] T. Zhang, H. N. Chen, Y. Bai, S. Xiao, L. Zhu, C. Hu, Q. Z. Xue, S. H. Yang, Nano Energy 2016, 26, 620-630.

[70] H. J. Snaith, A. Abate, J. M. Ball, G. E. Eperon, T. Leijtens, N. K. Noel, S. D. Stranks, J. T. W. Wang, K. Wojciechowski, W. Zhang, J. Phys. Chem. Lett. 2014, 5, 15111515 . 
Adv. Mater. 2017, DOI: 10.1002/adma.201702838

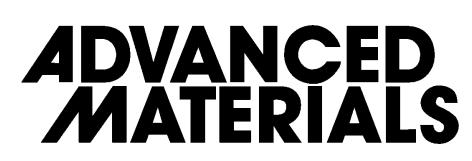

[71] Z. Xiao, Y. Yuan, Y. Shao, Q. Wang, Q. Dong, C. Bi, P. Sharma, A. Gruverman, J. Huang, Nat. Mater. 2015, 14, 193-198.

[72] R. Gottesman, E. Haltzi, L. Gouda, S. Tirosh, Y. Bouhadana, A. Zaban, E. Mosconi, F. De Angelis, J. Phys. Chem. Lett. 2014, 5, 2662-2669.

[73] J. G. Labram, D. H. Fabini, E. E. Perry, A. J. Lehner, H. Wang, A. M. Glaudell, G. Wu, H. Evans, D. Buck, R. Cotta, L. Echegoyen, F. Wudl, R. Seshadri, M. L. Chabinyc, J. Phys. Chem. Lett. 2015, 6, 3565-3571.

[74] J. G. Labram, Y.-H. Lin, T. D. Anthopoulos, Small 2015, 11, 5472-5482.

[75] C. H. Ahn, J. M. Triscone, J. Mannhart, Nature 2003, 424, 1015-1018.

[76] J. Mannhart, D. G. Schlom, Science 2010, 327, 1607.

[77] H. Y. Hwang, Y. Iwasa, M. Kawasaki, B. Keimer, N. Nagaosa, Y. Tokura, Nat. Mater. 2012, 11, 103-113.

[78] C. Woltmann, T. Harada, H. Boschker, V. Srot, P. A. van Aken, H. Klauk, J. Mannhart, Phys. Rev. Appl. 2015, 4, 064003.

[79] P. D. Eerkes, W. G. van der Wiel, H. Hilgenkamp, Appl. Phys. Lett. 2013, 103, 201603.

[80] W.-N. Lin, J.-F. Ding, S.-X. Wu, Y.-F. Li, J. Lourembam, S. Shannigrahi, S.-J. Wang, T. Wu, Adv. Mater. Interfaces 2014, 1, 201300001.

[81] D. B. Mitzi, C. A. Feild, W. T. A. Harrison, A. M. Guloy, Nature 1994, 369, 467-469.

[82] C. R. Kagan, D. B. Mitzi, C. D. Dimitrakopoulos, Science 1999, 286, 945.

[83] N.-G. Park, Mater. Today 2015, 18, 65-72.

[84] D. B. Mitzi, K. Chondroudis, C. R. Kagan, IBM J. Res. Dev. 2001, 45, 29-45.

[85] D. B. Mitzi, C. A. Feild, Z. Schlesinger, R. B. Laibowitz, J. Solid State Chem. 1995, 114, 159-163.

[86] C. C. Stoumpos, C. D. Malliakas, M. G. Kanatzidis, Inorg. Chem. 2013, 52, 90199038.

[87] H. Sirringhaus, P. J. Brown, R. H. Friend, M. M. Nielsen, K. Bechgaard, B. M. W. Langeveld-Voss, A. J. H. Spiering, R. A. J. Janssen, E. W. Meijer, P. Herwig, D. M. de Leeuw, Nature 1999, 401, 685-688.

[88] T. Matsushima, S. Hwang, A. S. D. Sandanayaka, C. Qin, S. Terakawa, T. Fujihara, M. Yahiro, C. Adachi, Adv. Mater. 2016, 28, 10275-10281.

[89] Y. Mei, C. Zhang, Z. V. Vardeny, O. D. Jurchescu, MRS Commun. 2015, 5, 297-301.

[90] Y. Wu, J. Li, J. Xu, Y. Du, L. Huang, J. Ni, H. Cai, J. Zhang, RSC Adv. 2016, 6, 16243-16249. 
Adv. Mater. 2017, DOI: 10.1002/adma.201702838

\section{ADVANCED}

[91] D. Shi, V. Adinolfi, R. Comin, M. J. Yuan, E. Alarousu, A. Buin, Y. Chen, S.

Hoogland, A. Rothenberger, K. Katsiev, Y. Losovyj, X. Zhang, P. A. Dowben, O. F.

Mohammed, E. H. Sargent, O. M. Bakr, Science 2015, 347, 519-522.

[92] S. P. Senanayak, B. Yang, T. H. Thomas, N. Giesbrecht, W. Huang, E. Gann, B. Nair, K. Goedel, S. Guha, X. Moya, C. R. McNeill, P. Docampo, A. Sadhanala, R. H. Friend, H. Sirringhaus, Sci. Adv. 2017, 3, e1601935.

[93] Y. H. Zhou, C. Fuentes-Hernandez, J. Shim, J. Meyer, A. J. Giordano, H. Li, P. Winget, T. Papadopoulos, H. Cheun, J. Kim, M. Fenoll, A. Dindar, W. Haske, E. Najafabadi, T. M. Khan, H. Sojoudi, S. Barlow, S. Graham, J. L. Bredas, S. R. Marder, A. Kahn, B. Kippelen, Science 2012, 336, 327-332.

[94] J. Smith, R. Hamilton, Y. Qi, A. Kahn, D. D. C. Bradley, M. Heeney, I. McCulloch, T. D. Anthopoulos, Adv. Funct. Mater. 2010, 20, 2330-2337.

[95] B. Conings, J. Drijkoningen, N. Gauquelin, A. Babayigit, J. D'Haen, L. D'Olieslaeger, A. Ethirajan, J. Verbeeck, J. Manca, E. Mosconi, F. D. Angelis, H.-G. Boyen, $A d v$. Energy Mater. 2015, 5, 1500477-n/a.

[96] G. E. Eperon, S. D. Stranks, C. Menelaou, M. B. Johnston, L. M. Herz, H. J. Snaith, Energy. Environ. Sci. 2014, 7, 982-988.

[97] A. R. Yusoff, H. P. Kim, X. Li, J. Kim, J. Jang, M. K. Nazeeruddin, Adv. Mater. 2016, 1602940.

[98] T. D. Anthopoulos, C. Tanase, S. Setayesh, E. J. Meijer, J. C. Hummelen, P. W. M. Blom, D. M. de Leeuw, Adv. Mater. 2004, 16, 2174-2179.

[99] T. D. Anthopoulos, D. M. de Leeuw, E. Cantatore, S. Setayesh, E. J. Meijer, C. Tanase, J. C. Hummelen, P. W. M. Blom, Appl. Phys. Lett. 2004, 85, 4205-4207.

[100] G. Xing, N. Mathews, S. S. Lim, N. Yantara, X. Liu, D. Sabba, M. Grätzel, S. Mhaisalkar, T. C. Sum, Nat. Mater. 2014, 13, 476-480.

[101] N. Wang, L. Cheng, R. Ge, S. Zhang, Y. Miao, W. Zou, C. Yi, Y. Sun, Y. Cao, R. Yang, Y. Wei, Q. Guo, Y. Ke, M. Yu, Y. Jin, Y. Liu, Q. Ding, D. Di, L. Yang, G. Xing, H. Tian, C. Jin, F. Gao, R. H. Friend, J. Wang, W. Huang, Nat. Photon. 2016, 10, 699-704.

[102] Z.-K. Tan, R. S. Moghaddam, M. L. Lai, P. Docampo, R. Higler, F. Deschler, M. Price, A. Sadhanala, L. M. Pazos, D. Credgington, F. Hanusch, T. Bein, H. J. Snaith, R. H. Friend, Nat. Nano. 2014, 9, 687-692.

[103] L. Dou, Y. Yang, J. You, Z. Hong, W.-H. Chang, G. Li, Y. Yang, Nat. Commun. 2014, 5, 5404. 
Adv. Mater. 2017, DOI: 10.1002/adma.201702838

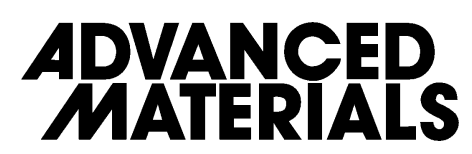

[104] H. T. Wei, Y. J. Fang, P. Mulligan, W. Chuirazzi, H. H. Fang, C. C. Wang, B. R. Ecker, Y. L. Gao, M. A. Loi, L. Cao, J. S. Huang, Nat. Photon. 2016, 10, 333-339.

[105] S. Yakunin, M. Sytnyk, D. Kriegner, S. Shrestha, M. Richter, G. J. Matt, H. Azimi, C. J. Brabec, J. Stangl, M. V. Kovalenko, W. Heiss, Nat. Photon. 2015, 9, 444-U44.

[106] F. Li, C. Ma, H. Wang, W. Hu, W. Yu, A. D. Sheikh, T. Wu, Nat. Commun. 2015, 6, 8238.

[107] Y. Lee, J. Kwon, E. Hwang, C.-H. Ra, W. J. Yoo, J.-H. Ahn, J. H. Park, J. H. Cho, Adv. Mater. 2015, 27, 41-46.

[108] X. Y. Chin, D. Cortecchia, J. Yin, A. Bruno, C. Soci, Nat. Commun. 2015, 6.

[109] S. Du, G. Li, X. Cao, Y. Wang, H. Lu, S. Zhang, C. Liu, H. Zhou, Adv. Electron. Mater. 2017, 1600325.

[110] Y. Yu, Y. T. Zhang, Z. Zhang, H. T. Zhang, X. X. Song, M. X. Cao, Y. L. Che, H. T. Dai, J. B. Yang, J. L. Wang, H. Zhang, J. Q. Yao, J. Phys. Chem. Lett. 2017, 8, 445451.

[111] E. C. P. Smits, S. Setayesh, T. D. Anthopoulos, M. Buechel, W. Nijssen, R. Coehoorn, P. W. M. Blom, B. de Boer, D. M. de Leeuw, Adv. Mater. 2007, 19, 734-738.

[112] M. Ullah, Y. H. Lin, K. Muhieddine, S. C. Lo, T. D. Anthopoulos, E. B. Namdas, Adv. Opt. Mater. 2016, 4, 231-237.

[113] J. Zaumseil, R. H. Friend, H. Sirringhaus, Nat. Mater. 2006, 5, 69-74.

[114] J. Zaumseil, C. R. McNeill, M. Bird, D. L. Smith, P. P. Ruden, M. Roberts, M. J. McKiernan, R. H. Friend, H. Sirringhaus, J. Appl. Phys. 2008, 103, 064517.

[115] C. M. Sutter-Fella, Y. Li, M. Amani, J. W. Ager, F. M. Toma, E. Yablonovitch, I. D. Sharp, A. Javey, Nano Lett. 2016, 16, 800-806.

[116] M. Muccini, Nat. Mater. 2006, 5, 605-613.

[117] A. T. Mallajosyula, K. Fernando, S. Bhatt, A. Singh, B. W. Alphenaar, J.-C. Blancon, W. Nie, G. Gupta, A. D. Mohite, Appl. Mater. Today 2016, 3, 96-102.

[118] D. Vak, K. Hwang, A. Faulks, Y.-S. Jung, N. Clark, D.-Y. Kim, G. J. Wilson, S. E. Watkins, Adv. Energy Mater. 2015, 5, 1401539-n/a.

[119] A. T. Barrows, A. J. Pearson, C. K. Kwak, A. D. F. Dunbar, A. R. Buckley, D. G. Lidzey, Energy. Environ. Sci. 2014, 7, 2944-2950.

[120] Z. L. Ku, Y. G. Rong, M. Xu, T. F. Liu, H. W. Han, Sci. Rep. 2013, 3, 3132.

[121] M. I. Asghar, J. Zhang, H. Wang, P. D. Lund, Renew. Sust. Energ. Rev. 2017, 77, 131146. 
Adv. Mater. 2017, DOI: 10.1002/adma.201702838

\section{ADVANCED}

[122] S. Wang, Y. Jiang, Emilio J. Juarez-Perez, Luis K. Ono, Y. Qi, Nat. Energy 2016, 2, 16195.

[123] Y. Yang, J. You, Nature 2017, 544, 155-156.

[124] D. Bryant, N. Aristidou, S. Pont, I. Sanchez-Molina, T. Chotchunangatchaval, S. Wheeler, J. R. Durrant, S. A. Haque, Energy. Environ. Sci. 2016, 9, 1655-1660.

[125] M. Saliba, T. Matsui, J.-Y. Seo, K. Domanski, J.-P. Correa-Baena, M. K. Nazeeruddin, S. M. Zakeeruddin, W. Tress, A. Abate, A. Hagfeldt, M. Gratzel, Energy. Environ. Sci. 2016, 9, 1989-1997.

[126] G. Grancini, C. Roldan-Carmona, I. Zimmermann, E. Mosconi, X. Lee, D. Martineau, S. Narbey, F. Oswald, F. De Angelis, M. Graetzel, M. K. Nazeeruddin, Nat. Commun. 2017, 8, 15684.

[127] C.-H. Chiang, C.-G. Wu, ChemSusChem 2016, 9, 2666-2672.

[128] J. You, L. Meng, T.-B. Song, T.-F. Guo, Y. Yang, W.-H. Chang, Z. Hong, H. Chen, H. Zhou, Q. Chen, Y. Liu, N. De Marco, Y. Yang, Nat. Nano. 2016, 11, 75-81.

[129] Y. Han, S. Meyer, Y. Dkhissi, K. Weber, J. M. Pringle, U. Bach, L. Spiccia, Y.-B. Cheng, J. Mater. Chem. A 2015, 3, 8139-8147.

[130] M. R. Filip, S. Hillman, A. A. Haghighirad, H. J. Snaith, F. Giustino, J. Phys. Chem. Lett. 2016, 7, 2579-2585.

[131] Z. Shi, J. Guo, Y. Chen, Q. Li, Y. Pan, H. Zhang, Y. Xia, W. Huang, Adv. Mater. 2017, 29, 1605005-n/a.

[132] G. Flora, D. Gupta, A. Tiwari, Interdiscip. Toxicol. 2012, 5, 47-58.

[133] A. Babayigit, A. Ethirajan, M. Muller, B. Conings, Nat. Mater. 2016, 15, 247-251.

[134] N. R. Council, D. E. L. Studies, B. E. S. Toxicology, C. Toxicology, C. P. H. R. R. L. E. D. O. D. F. R. Personnel, Potential Health Risks to DOD Firing-Range Personnel from Recurrent Lead Exposure, National Academies Press, 2013.

[135] I. R. Benmessaoud, A.-L. Mahul-Mellier, E. Horvath, B. Maco, M. Spina, H. A. Lashuel, L. Forro, Toxicol. Res. 2016, 5, 407-419.

[136] A. Babayigit, D. Duy Thanh, A. Ethirajan, J. Manca, M. Muller, H.-G. Boyen, B. Conings, 2016, 6, 18721.

[137] J. Gong, S. B. Darling, F. You, Energy. Environ. Sci. 2015, 8, 1953-1968.

[138] J. Zhang, X. Gao, Y. Deng, B. Li, C. Yuan, ChemSusChem 2015, 8, 3882-3891.

[139] J. Zhang, X. Gao, Y. Deng, Y. Zha, C. Yuan, Sol. Energ. Mat. Sol. Cells 2017, 166, 917. 
Adv. Mater. 2017, DOI: 10.1002/adma.201702838

[140] L. Serrano-Lujan, N. Espinosa, T. T. Larsen-Olsen, J. Abad, A. Urbina, F. C. Krebs, Adv. Energy Mater. 2015, 5, 1501119.

[141] B. Hailegnaw, S. Kirmayer, E. Edri, G. Hodes, D. Cahen, J. Phys. Chem. Lett. 2015, 6, 1543-1547. 
Figure 1. Crystal structures of (a) cubic, (b) tetragonal, and (c) orthorhombic phases of methylammonium lead iodide $\mathrm{CH}_{3} \mathrm{NH}_{3} \mathrm{PbI}_{3}$. Dashed rectangles represent the unit cells. The $\mathrm{BX}_{6}\left(\mathrm{PbI}_{6}\right.$ in this case) units are depicted as shaded octahedral. The top and bottom panels are viewed along the $\langle 100\rangle$ and $\langle 001\rangle$ directions, respectively. Reproduced from F. Brivio et al., Lattice dynamics and vibrational spectra of the orthorhombic, tetragonal, and cubic phases of methylammonium lead iodide, Phys. Rev. B 2015, 92, 144308 (2014), ${ }^{[49]}$ under the Creative Commons Attribution 3.0 License. (d) Electronic band structure and (e) total and partial density of states (DOS) of $\alpha-\mathrm{CH} 3 \mathrm{NH} 3 \mathrm{PbI} 3$ calculated by DFT-PBE. Reproduced with permission. ${ }^{[41]}$ Copyright 2014, AIP Publishing. (f) Bonding diagram of a $\mathrm{PbI}_{6}$ unit showing the formation of molecular orbitals. Reproduced with permission. ${ }^{[42]}$ Copyright 2003, APS Publications. (g) Schematic diagram showing the migration of the two major mobile ionic species: iodide and methylammonium ions (I- and MA+, respectively). Reproduced with permission. ${ }^{[36]}$ Copyright 2016, ACS Publications.

a Cubic
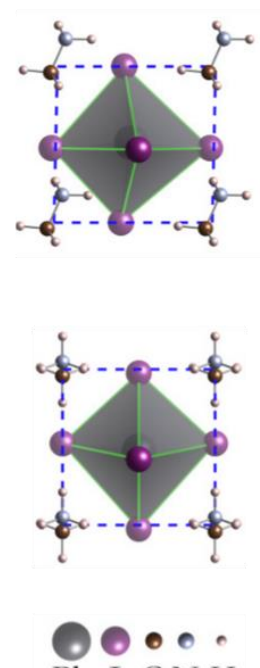

b Tetragonal
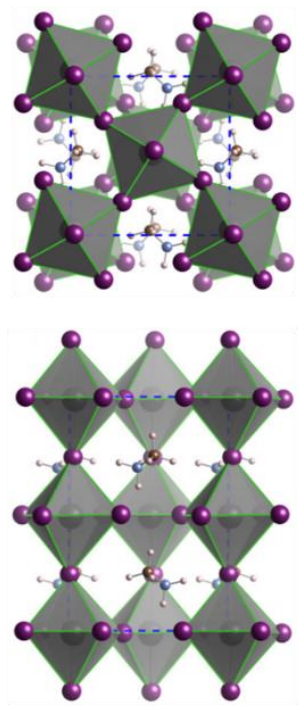

\section{Orthorhombic}
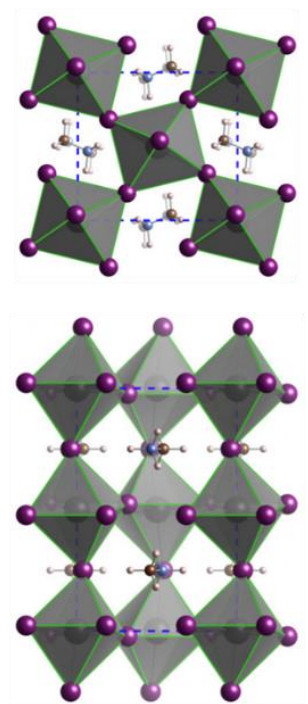

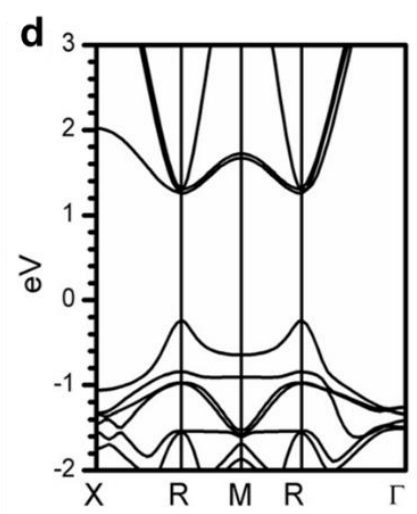

e

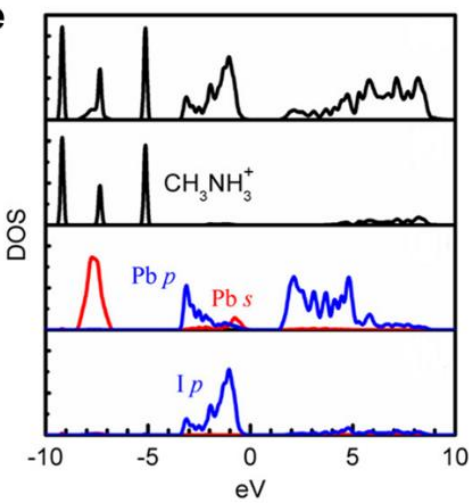

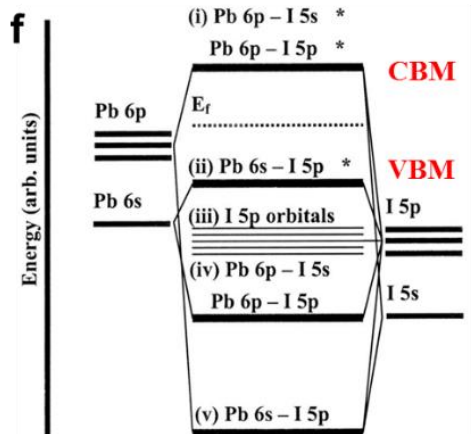

g

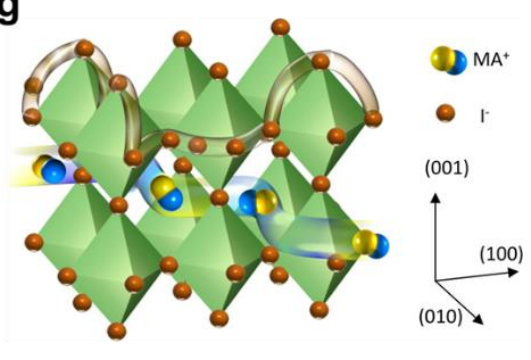


Figure 2. (a) Schematic of the $2 \mathrm{D} \mathrm{PEASnI}_{4}$ perovskites. Reproduced with permission. ${ }^{[82]}$ Copyright 1999, AAAS. (b) A TG-BC PEASnI 4 based MHP transistor using $\mathrm{NH}_{3} \mathrm{I}-\mathrm{SAM}$ as the substrate modification layer. (c) A representative set of I-V characterizations (left: output characteristics; right: transfer characteristics) for the transistor shown in (b). Reproduced with permission. ${ }^{[88]}$ Copyright 2016, Wiley \& Sons. (d) Transfer characteristics of $\mathrm{MAPbI}_{3}$ transistors in a BG-TC configuration (inset), measured at various temperatures between 150 and $250 \mathrm{~K}$. (e) Gate voltage (top) and source-drain current (bottom) as a function of time measured at $150 \mathrm{~K}$ for the $\mathrm{MAPbI}_{3}$ transistor shown in (d). (f) Time-dependent source-drain current at various temperatures from 155 to $220 \mathrm{~K}$ under the same gate-voltage pulse shown in (e). Reproduced with permission. ${ }^{[73]}$ Copyright 2015, ACS Publications. (g) Transfer curves for $\mathrm{MAPbI}_{3}$ transistors with different surface treatments. (h) Transfer characteristics of PEIEtreated $\mathrm{MAPbI}_{3}$ transistors measured at room temperature $(300 \mathrm{~K})$. (i) Dielectric loss measurement as a function of frequency and temperature measured for $\mathrm{MAPbI}_{3}$ based capacitor. Reproduced with permission. ${ }^{[92]}$ Copyright 2017, AAAS.
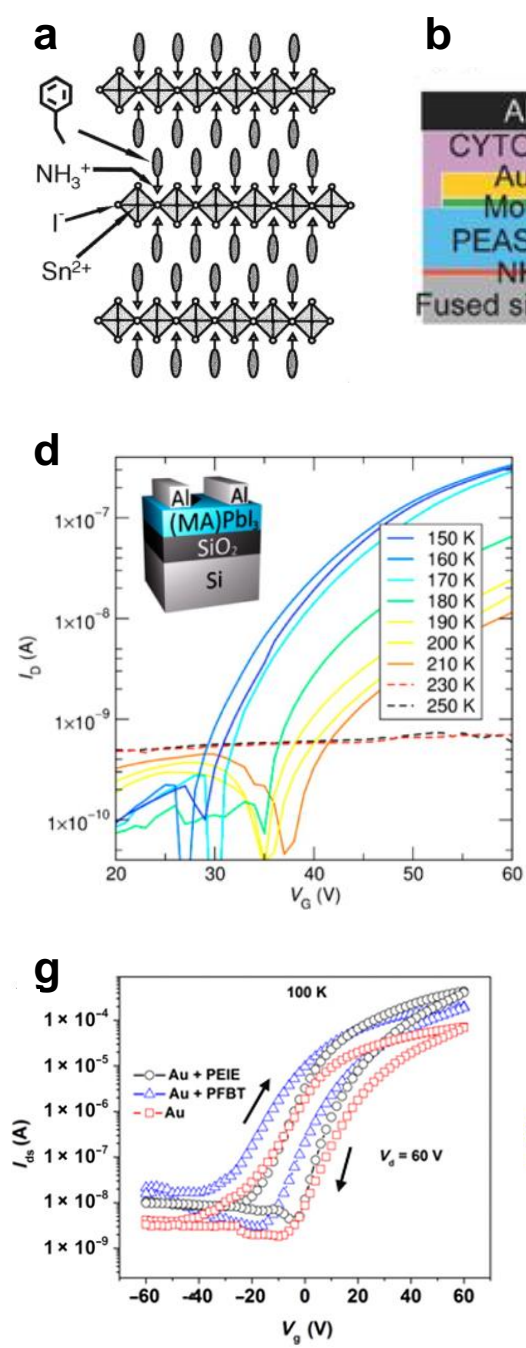
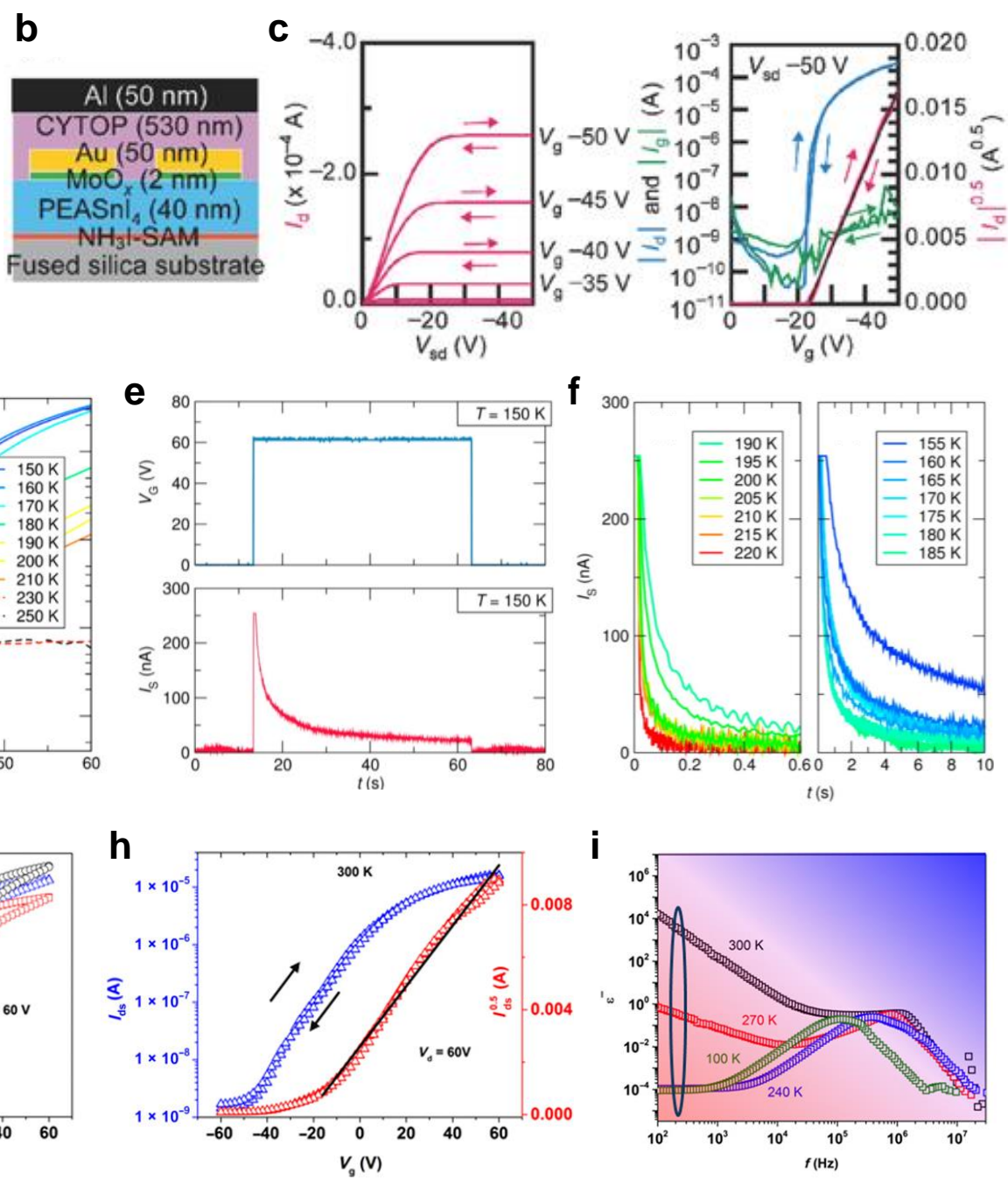
Figure 3. (a) Schematic of a BG-TC MAPbI 3 phototransistor. (b) Transfer characteristics of the phototransistor shown in (a), measured under dark condition (black and red) and light illumination (blue and magenta). (c) Dynamic photocurrent response (top) showing $~ 6.5 \mu$ s rise and $\sim 5.0 \mu$ s decay time (bottom left), and photoresponse under various gate voltages (bottom right - red: $\mathrm{V}_{\mathrm{G}}=0 \mathrm{~V}$; blue: $\mathrm{V}_{\mathrm{G}}=-30 \mathrm{~V}$; magenta: $\left.\mathrm{V}_{\mathrm{G}}=-40 \mathrm{~V}\right)$. Reproduced with permission. ${ }^{[106]}$

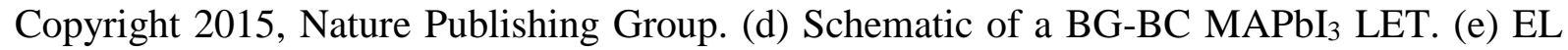
spectra of $\mathrm{MAPbI}_{3}$ LETs measured at various temperatures from 78 to $178 \mathrm{~K}$. (f) Photos of light emission from $\mathrm{MAPbI}_{3}$ LETs under different $\mathrm{V}_{\mathrm{G}}$ and $\mathrm{V}_{\mathrm{D}}$ bias conditions. Reproduced with permission. ${ }^{[108]}$ Copyright 2015, Nature Publishing Group.

a

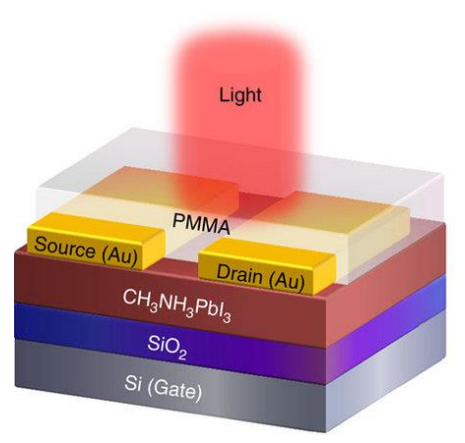

b

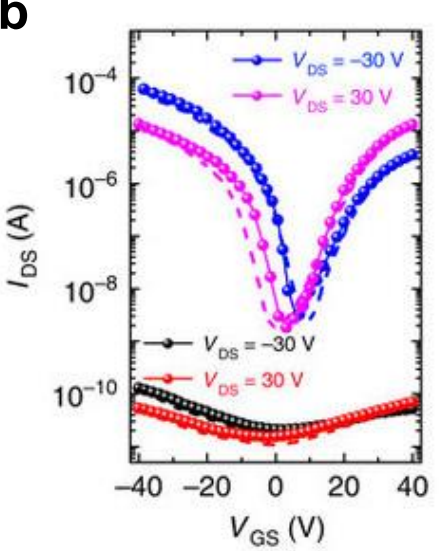

d

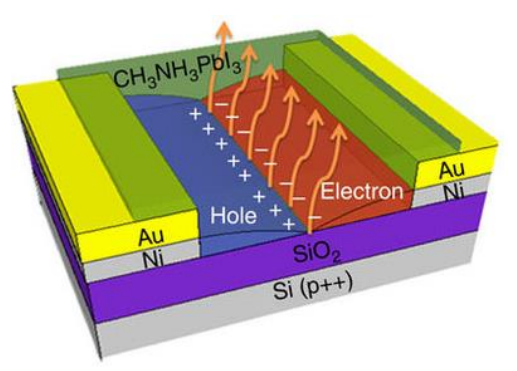

e

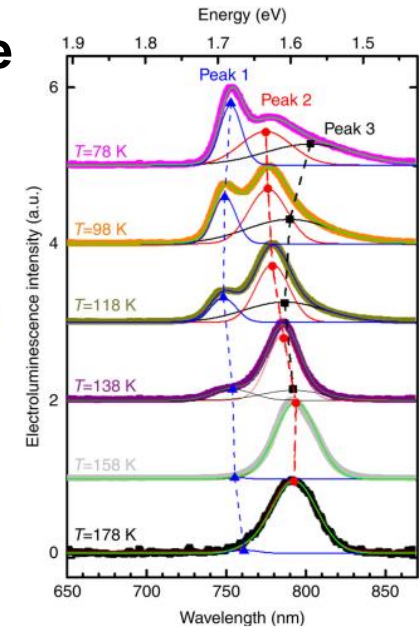

C
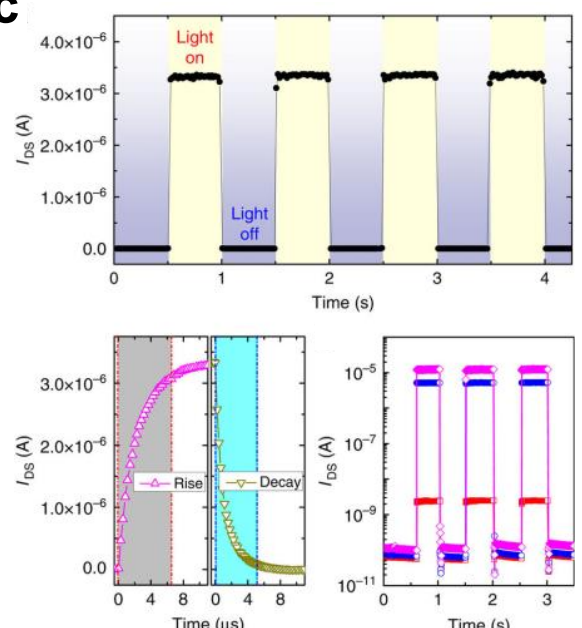

$\mathbf{f}$

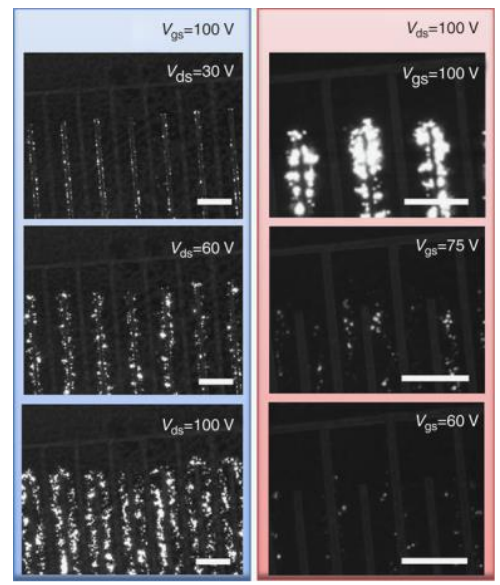


Yen-Hung Lin received his $\mathrm{PhD}$ in Experimental Solid State Physics from Imperial College London, UK (2015), under the supervision of Prof Thomas Anthopoulos. Prior to coming to the UK, he was a senior engineer at AU Optronics (Taiwan), working on mobile display design. After his $\mathrm{PhD}$, he started his first postdoctoral position in the same group, working on highmobility oxide transistor, organic electret non-volatile memory and high-sensitivity biosensor till December 2016. In January 2017, he joined Prof Henry Snaith's group at the University of Oxford, where his research focuses on hybrid perovskite energy harvesting and optoelectronic applications.

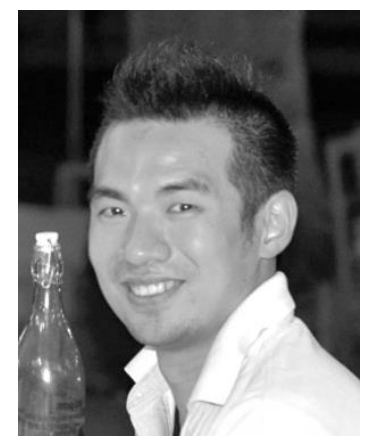

Pichaya Pattanasattayavong obtained his BEng in Nano-Engineering (First Class Honors, 2009) from Chulalongkorn University, Thailand. Awarded with a scholarship from Anandamahidol Foundation under the Royal Patronage of His Majesty the King of Thailand, he went on to receive his MSc (2010) and PhD (2014) in Physics from Imperial College London, UK. In 2015, he joined the School of Molecular Science and Engineering, Vidyasirimedhi Institute of Science and Technology (VISTEC), Thailand, as a faculty member. His current research interests include novel solution-processable materials for opto/electronic applications as well as semiconductor physics and charge transport physics of novel materials and devices.

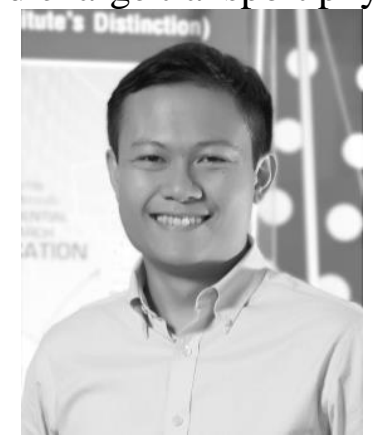

Thomas Anthopoulos received a BEng in Medical Engineering and a PhD in Physical Electronics from Staffordshire University (UK). After a two year postdoctoral appointment at the University of St. Andrews (UK), he joined Philips Research Laboratories (The Netherlands). In 2006 he moved to the Department of Physics at Imperial College London following the ward of an Advanced EPSRC Fellowship. He joined the King Abdullah University of Science and Technology (KAUST) in the Kingdom of Saudi Arabia in 2017. His current research interests are diverse and involve the development of novel nano-patterning methods for large-volume plastic nanoelectronics and the physics of functional materials \& devices.

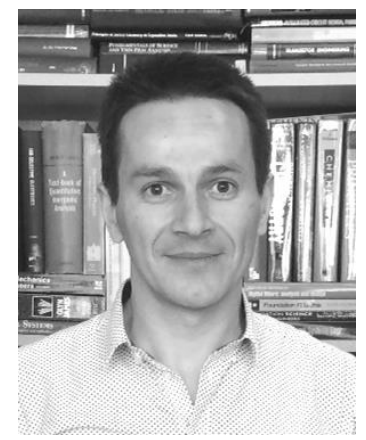


Adv. Mater. 2017, DOI: 10.1002/adma.201702838

\section{ADVANCED}

The combination of extremely attractive electronic and optical properties and their unmatched processing versatility have driven metal-halide perovskites (MHPs) to the forefront of functional electronic materials research with envisioned applications spanning across several technology sectors. This Research News article summarizes recent advances in the use of MHPs in the area of transistor and transistor-related applications.

Keyword perovskites; solar cells; thin-film transistors; charge transport; optoelectronics

Yen-Hung Lin*, Pichaya Pattanasattayavong*, and Thomas Anthopoulos*

Title Metal-Halide Perovskite Transistors for Printed Electronics: Challenges and Opportunities

$\mathrm{ABX}_{3}$ Hybrid Perovskites

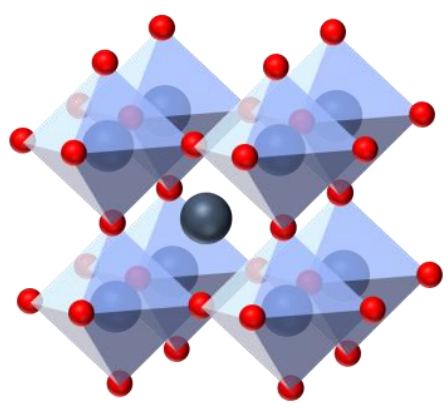

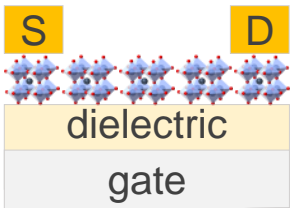
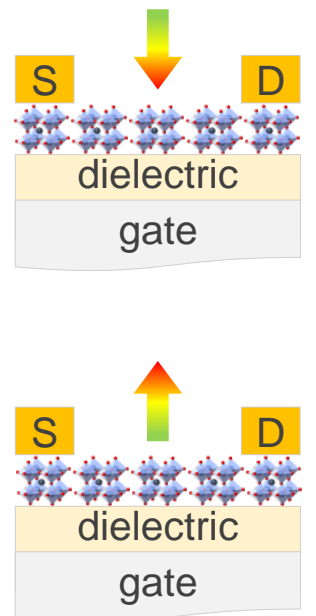
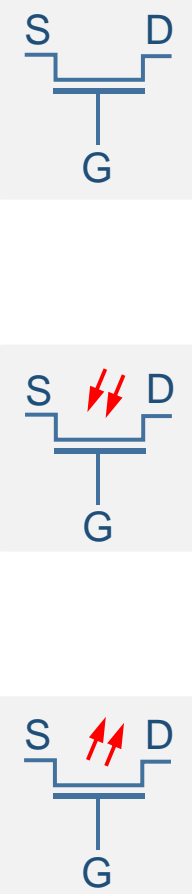

TOC Graphic 